\title{
Article \\ A Game Theoretic Framework for Surplus Food Distribution in Smart Cities and Beyond
}

\author{
Surja Sanyal ${ }^{1,+} \oplus^{\circ}$, Vikash Kumar Singh ${ }^{2,+} \oplus$, Fatos Xhafa ${ }^{3, *,+} \oplus$, Banhi Sanyal ${ }^{4,+}$ and Sajal Mukhopadhyay ${ }^{1,+}$ \\ 1 Department of Computer Science and Engineering, National Institute of Technology Durgapur, \\ Durgapur 713209, West Bengal, India; hi.surja06@gmail.com (S.S.); sajal@cse.nitdgp.ac.in (S.M.) \\ 2 School of Computer Science and Engineering, VIT-AP University, Amaravati 522237, Andhra Pradesh, India; \\ vikash.singh@vitap.ac.in \\ 3 Department of Computer Science, Universitat Politècnica de Catalunya, 08034 Barcelona, Spain \\ 4 Department of Computer Science and Engineering, National Institute of Technology Rourkela, \\ Rourkela 769001, Odisha, India; banhisanya19@gmail.com \\ * Correspondence: fatos@cs.upc.edu \\ + These authors contributed to this work.
}

check for updates

Citation: Sanyal, S.; Kumar Singh, V.; Xhafa, F.; Sanyal, B.; Mukhopadhyay S. A Game Theoretic Framework for Surplus Food Distribution in Smart Cities and Beyond. Appl. Sci. 2021, 11, 5058. https://doi.org/10.3390/ app11115058

Academic Editor: Dimitris P. Makris

Received: 6 May 2021

Accepted: 25 May 2021

Published: 30 May 2021

Publisher's Note: MDPI stays neutral with regard to jurisdictional claims in published maps and institutional affiliations.

Copyright: (c) 2021 by the authors. Licensee MDPI, Basel, Switzerland. This article is an open access article distributed under the terms and conditions of the Creative Commons Attribution (CC BY) license (https:// creativecommons.org/licenses/by/ $4.0 /)$.
Featured Application: This is a relatively less researched topic around the globe. Our research and the included algorithm will hugely benefit current and upcoming surplus food distribution activities, provide core support to existing and future food communities, as well as address the food insecurity and wastage issues of the world.

Abstract: Food waste is currently a major challenge for the world. It is the precursor to several socioeconomic problems that are plaguing modern society. To counter and to, simultaneously, stand by the undernourished, surplus food redistribution has surfaced as a viable solution. Information and Communications Technology (ICT)-mediated food redistribution is a highly scalable approach and it percolates into the lives of the masses far better. Even if ICT is not brought into the picture, the presence of food surplus redistribution in developing countries such as India is scarce and is limited to only a few of the major cities. The discussion of a surplus food redistribution framework under strategic settings is a less discussed topic around the globe. This paper aims to address a surplus food redistribution framework under strategic settings, thereby facilitating a smoother exchange of surplus food in the smart cities of developing countries and beyond. As ICT is seamlessly available in smart cities, the paper aims to focus the framework in these cities. However, this can be extended beyond the smart cities to places with greater human involvement.

Keywords: food surplus; surplus food distribution; food recovery; food waste; food sharing; food waste management; smart cities; ICT-mediation; game theory; double-sided market; sustainability; scalability; donation traceability; food recoverability

\section{Introduction}

For the last decade, food waste has been a major contributor towards several socioeconomic problems [1,2], including, but not limited to, global warming, greenhouse gas emissions, water wastage, soil degradation, farmer suicides, price fluctuations, black marketing, and hoarding. On a global scale, more than $30 \%$ of all edible products end up as waste [3]. Each year, this wastage amounts to billions of tons of food, out of which near $60 \%$ is avoidable [4]. One of the solutions that can deal with this underrated yet serious problem of food wastage is surplus food redistribution. Distributing surplus food to areas where it is in deficit utilizes the generation of food waste at the surplus end and alleviates hunger at the deficit end. While this may not be a solution to the whole situation, it targets the $60 \%$ avoidable food waste into a win-win scenario for society as well as the economy of the land. Information and Communications Technology (ICT) has taken this a step further [5] and 
made the redistribution activity smoother by connecting the donors with the receivers and the available volunteers, by minimizing human interference as far as possible. The use of ICT brings the very desirable properties of sustainability and, more importantly, scalability to the table. ICT mediation in food redistribution is an extremely important contemporary topic [6] and is gaining fast popularity around the world due to its numerous upsides. In the smart cities of developing countries such as India, however, a lot remains to be done as the presence of food redistribution movements mediated by ICT is scarce and only limited to a few major cities. The discussion of a surplus food redistribution framework under strategic settings is a less discussed topic around the globe.

This paper aims at addressing a surplus food redistribution framework under strategic settings, thereby facilitating a smoother exchange of surplus food in the smart cities of developing countries and beyond. This framework will be available via a handheld devicebased app, a game theory-assisted ICT-based platform, that will allow users, hereafter referred to as Agents, to raise food requests as donors, receivers, and/or volunteers. This app will take other required information such as location, surplus food types, their expiry dates (packaged food items), preparation times (cooked food items), pickup, drop, donation, receipt related information, etc. as inputs as well. Just before the request submission, the agent will be able to set preferences for donation, pickup, or volunteering, as applicable. As ICT is seamlessly available in smart cities, the paper aims to focus the framework in these cities. However, this can be extended beyond smart cities to places with greater human involvement.

This paper is organized as follows. The rest of this section (Section 1) presents the related work in this field. The system model and the proposed mechanism are discussed in Section 2. The mechanism has been analyzed in Section 3 and its simulation results are presented in Section 4. A discussion of the outcome has been put forward in Section 5, followed by conclusions and future work in Section 6.

\subsection{Related Work}

The foundation of our work already exists in the form of establishing food redistribution as one of the leading solutions of dealing with food wastage and ICT mediation is a great add-on to boost the surplus movement. However, work on the algorithms used to match the donors with the receivers remains elusive and is the main agenda of our paper.

\subsubsection{Literature Review}

Work has been conducted in this field that evaluates the efficacy of the usage of ICT in food redistribution or carries out survey-based research on the current usage of ICT by different food sharing communities. The perishable nature of products has forced changes to the food supply chain design to maximize shelf-life and minimize food waste [7].

The rapid global growth of volunteer-dependent and ICT-based platform-mediated surplus food redistribution initiatives has been identified in [8]. This research captured both the worlds of dominant interests and root cause mitigating best practices that are traded off in such food movements. The involvement and contributions of cultures, organizational facts and internal experiences have also been explored [9]. While the study first reviewed the food waste management system of Singapore and the prevailing socio-political context, it also went on to discuss all formats of people's interactions with food waste related problems. Reduction in food waste production as an approach for mitigating climate change attempted by grassroots initiatives aims to prevent avoidable food waste and redistribute surplus food for consumption, as presented in [10]. These low budget initiatives rely heavily on volunteers to curb their costs. ICT, in terms of social media, acts as another tool in their success in surplus food movement. It has been suggested that environmental sustainability is best supported by an approach called the Social Supermarket, in which a body for handling the surplus of a city works with several food distributors to acquire surplus food either directly from the donors or through a charitable government body and redistributes it to the needy [11]. However, economically, 
the study reveals that the concept of Food Bag Center is the most efficient, in which a body collects the surplus food of a city and redistributes it in grocery bags to financially challenged people. A unique study [12] reported an attempt at the complicated task of reducing consumer food waste at cafeterias using the combo of ICTs and IoTs. Lunch lines containing sensors that track food wastage, which is later shown by an app on each consumer's mobile, revealed an average of $3 \%$ of food wasted by the customers. Surplus food databases of market value have been created [13] and the prevailing practices of surplus food management assessed. Propelled by a Thailand food rescue organization, the study went on to make several recommendations in the process that strengthened the organization's ties with the donors and the receivers. As mentioned, partnering with a food sharing app OLIO (https:/ / olioex.com/, accessed on 24 December 2020), an analysis of the social network of the app was presented [2]. The analysis revealed the formation of new relationships that divert from the expected donor-receiver ones. This may prove pivotal for policy makers who aim to analyze and encourage ICT-assisted food redistribution. Recent studies $[14,15]$ discuss the legislation policies affecting food wastage directly or indirectly in the European Union. They argued that although the existing policies do facilitate better food redistribution by means of mitigating existing challenges to smoothout the process, they do not address the issue at the root level in terms of prevention of surplus food generation. They pointed out that the food policies of the land affect proper food redistribution and food waste prevention. The use of ICT speeds up the redistribution process, provides high scalability of the operations and also attracts better quality surplus food [16]. Research [17] also documents the complexities and opportunities involved in food redistribution locally. The study also highlights the practices that can transform the way surplus food is perceived and revalued. There also has been research [18] on a specific South African mobile app named Food for Us (http: / / foodforus.co.za /, accessed on 24 December 2020). This app works on providing food to those in need and allowing small-scale producers to get their produce to markets. This paper reveals the need for developing a strong social networked system built around technological platforms such as this app to help find alternate markets for unsold farm produce. A valuable lesson is provided in [19] by contrasting images between different food handling practices. The study termed food as "an instigator and a tool" that helps in learning and re-learning health, happiness, and ecology related impacts. The study pondered on the need to know and pay attention to the details that help differentiate between food and waste. Food redistribution has been portrayed as a double-edged sword to fight against food insecurity and food waste [20]. The study discusses the efficacy of the anti-waste/pro-donation law of Italy in addressing both food waste and insecurity. It also points out that its effectiveness lies in bringing together the different actors in the food management process for tackling the food insecurity issue. The study notes the potential tensions that may soon be realized due to the use of different paths for food surplus utilization. The same concept encourages some people to donate expiring food items charitably, while others sell it at a discounted price. The concept of a peer-to-peer (P2P) food sharing system based on high internet usage and people interested in food sharing is well-studied [21]. This study acts as a base to identify future P2P food collection and redistribution zones and the actors they can attract. The creation and accumulation of networks of sharing individuals, as well as how digital platforms can aid in the scaling of such an approach keeping in mind the sustainability of such initiatives, has been assessed [22]. The scenario of sharing food in cities has also been directly assessed [23] and viewed as a field of experimentation and innovation. The study identifies places, leading approaches, common trends and notions that are involved and provides a basis for future research.

Adequate pricing for items having unpredictable demand and time-dependent usability has been observed as an interesting strategy leading to waste reduction [24]. It has been recognised [25] that ICTs do contribute towards a smoother transformation to sustainable food systems by increasing resource productivity, reducing inefficiencies, decreasing management costs, and improving food chain coordination. As a matter of fact, 
the contribution of ICT in the redistribution of surplus prepared or cooked food, which have a very short window of recoverability before they spoil, has been observed [16]. This study remarks on the ability of ICT-based platforms to rapidly locate surplus receivers who can put this food to good use. The study also examines how communities having different goals for food redistribution cooperate in implementing ICT-mediated solutions in food sharing activities. While it clearly highlights the scaling of new horizons by the use of ICTs, it also alerts about the moral hazards and social regulations that form around the redistribution of surplus food. Food sharing practices have been termed as "messy" [26] emphasizing that it includes diverse ranges of participants and practices that also vary over space and time and are connected via both physical and virtual platforms (ICTs). As stated previously, it is pointed out that an ICT intervention resulted in the recovery of surplus food at all stages of food production [6]. However, maximum recovery was noted in the retail stage. The study also credited the faster movement of surplus in ICTmediated redistribution. The urban food sharing habits and activities, including provision, consumption and redistribution of food, have been thoroughly studied by them as well. What constitutes food and what can be considered acceptable food practice have also been discussed and pushed to new limits. Regulations of the land and the involved food risk emerge as key factors to consider during such redistribution activities. Production beyond need, poor management, and bad consumer behaviours have been identified as the reasons that cause difficult challenges related to food wastage on a global scale [27]. The study also examines surplus food redistribution as a solution to this challenge in the United Kingdom and finds that there is a lot of scope for further improvement in efficiency. How food donation facilitates the transition towards a circular economy and brings together the diverse players of the process have been explored [28]. The study draws an important conclusion that multi-agent collaborations are the key towards a circular economy. The thesis [29] presented the different motives and interactions of the different actors involved in the act of food distribution. The study also brought into light the operational effects of the act and the challenges and alternatives to the donors. Another study [30] summarized the food redistribution initiatives implemented by individuals across more than ninety countries. The study evaluated these initiatives in terms of sustainability and created a database that depicts the transformation of the society towards sustainability.

The study [31] acknowledges the positive impact of ICT in food redistribution and also created a database of such food sharing activities across several cities, countries and continents in order to facilitate the identification and analysis of repetitive patterns and temporal trends in ICT-mediated surplus redistribution. Food sharing, coupled with structural changes along the production line and better consumer habits, has been deemed [32] as a potential solution towards reducing food waste. Food redistribution is predicted to mitigate the effects of the food crunch that will arise due to growing demands for food of the ever exploding population of the world and the limitation of natural resources. Prevailing food practices and waste generation rates have been rendered not only environmentally, but also economically and socially unsustainable in the long run. The study [33] establishes the fact that more than one out of eight people in the United States is affected with food insecurity in spite of around one-third of all food production going into landfills. The study acknowledges that food redistribution organizations do mitigate this insecurity, although more in some states of the country than in others. The study [34] also recognizes the positive impacts of food redistribution on the environment, economy, and society in Italy. Highly benefited areas were identified and profiles for such redistribution activities were built. The study [35] acknowledged the contrasting challenges of food waste and food insecurity in the US. Based on the analysis of the $\mathrm{K}-12$ school system in Maine, it was pointed out that very little is known about the strategies that schools use to handle the considerable amount of food waste that they produce. This paper suggested that several factors are considered in the choice of any waste reduction policies in schools. The study [36] studied the prevailing traceability practices of Stockholm's Stadsmission food bank. Although the then current practices proved to be sufficient to provide food safety and quality, potential for 
systematic errors was also detected. They pointed out the absence of temperature control at the donation and receipt points to be the main issue in the redistribution process. The study [37] observed the working of an Israeli food bank using a different logistical model from the other food banks. They have non-profit organizations (NPOs) as intermediaries that add fresh produce to the surplus, thereby improving the food value of the redistribution. However, this unique approach requires additional infrastructure and strict measures when compared to the simple surplus redistribution process, as noted by the study. The environmental impact of food redistribution from donation to consumption against that of alternative options such as landfilling and composting has been discussed [38]. Although the facts favoured composting, a better optimized food redistribution utilizing benefits of using the other alternative options in the process seemed to be a win-win solution for the future. Dynamic pricing of perishable goods [39] and better inventory policies for items whose prices are dependant on the item's remaining shelf-life [40] have been shown to benefit both revenue generation and waste reduction, making them attractive choices. In fact, models have been studied for items having different expiry dates and buyers opting for different items based on item costs and expiry dates [41].

The study [42] accepts that the unwise and inefficient use of food resources has rendered us in need for a transition towards sustainable practices. The study explores this transition towards a circular food system and discusses the problems and probable solutions for each stage of food production. The three phases of handling surplus food waste, namely, prevention, recovery, and recycling, have been highlighted [43]. This takes the utilization of surplus food waste to beyond human consumption. This paper also states that holistic changes in food production methods are the best approach towards sustainability in the long run. The results of ICT application to the various stages of food wastage have been studied, as previously stated [5]. Different features added to the base ICT platform attracted agents at different stages to participate in the surplus redistribution movement. However, low recoverability of food at the household level was noted as well. ICT solutions have also been identified [44] for efficiency through monitoring and assessment of environmental impact, enhanced transparency and traceability in the food system, and creation of a network between actors in the food chains to influence and change food practices. Multiple case studies have been explored to provide available surplus management options and the factors that make these options attractive and applicable [45]. The results of this study suggest the availability of several food redistribution options that are applicable over the recoverable window of food items. Certain recommendations were made for the improvement of food redistribution [46]. They recommend a systems operator at the national level to coordinate redistribution activities, proper food redistribution guidelines that cover safety and efficacy of the activity, sufficient funding for the same, and prioritizing food redistribution. The research [47] compares a food redistribution environment with and without a food bank and evaluates the effects of a food bank on the environment and the finance of the participants of the activity. The study establishes the superiority of having a food bank in the picture on both the parameters mentioned above. Re-Food (https:/ / www.re-food.org/en, accessed on 4 January 2021), a Portuguese food redistributor, has been studied [48] and it was found that logistic related issues stop it from fully eliminating food waste. The study also notes that the firm brings together people from different stages of the redistribution activity to adhere to a common cause that is the local elimination of food waste and hunger issues. There is research [49] on mathematical models of food circulation by food banks to analyze and optimize the effective and equitable distribution of food, i.e., food distributed to each service area should be proportional to the demand of food in that service area.

The concept of food redistribution and the principles that follow it have been put forward [50], and the food redistribution activities have been analyzed on that basis. This paper also suggested that encouragement for food businesses to donate the surplus they generate is an important step in handling the reducing surplus production of food. A Norwegian study [51] took the solution of food waste generation to beyond human 
redistribution and consumption. The study included approaches such as fodder for animals, biogas generation, and even compost. This stretches the utility of surplus beyond products for human consumption. However, it identified food redistribution as the most sustainable and appropriate approach for handling the surplus. One study [52] carried out in Finland calculated the number of cooked meals at up to 10,000 a year, and that of redistributed food bags as up to 270,000 bags a year by one organization, from donated surplus or redistributed food. This study suggested a possibility of improvement in food waste reduction strategies of the country. Government policies have been analyzed [53] with respect to handling food waste generation and overall people welfare and categorized them into policies that help achieve a relationship between both the above goals and that help achieve one of them while degrading the situation for the other. The study pointed out that there are policies that are categorized into both the above mentioned types. Thus, as it is inferred in the study, public health needs to be the main consideration when designing policies for food waste reduction and management.

Food rescue has been highlighted [54] as an initiative in the emergency food sector internationally in an attempt to reduce food waste and to improve supplies to providers and consumers. The steps through which food producers recover and donate their surplus food for redistribution to the food banks have been brought into light [55]. Although the research only covers Italy, it still provides valuable insights into the visceral operations of food organizations that relate to their tax savings, waste management, and society rapport. While accepting surplus food redistribution as a key solution to food waste reduction, one step ahead has been taken [56] by also suggesting a model for surplus food generation and management. The study also shows how to use this model to pinpoint food wastage mitigation options. Although food banks are a successful concept in the food management process, it has been noted that the government does not track its usage [57]. Although many conclude on several welfare reforms being the reason for the growth of food banks, the government is poised on their say that there is no strong evidence to suggest that. The study [58] covers the food redistribution systems that existed in China at around 200 BC. Through archaeological evidence, it documents that food was redistributed by the emperor to the subjects in various forms and notes the different dietary conditions of people at diverse status in the society. This study notes discrepancies between the passed regulation and the actuation of the redistribution process. The study also studied the redistribution to the those in need and noted a bias towards saving physically capable farmers rather than addressing to the needs of the economically endangered ones. It also sheds light on an exceptional method of redistribution used by the rulers to feed people of inferior status through feast leftovers. Another study [59] proposes a model to maximize the economical benefits of food redistribution for the retail donor organizations. The model suggests optimal time for withdrawing food items from shelves for redistribution and also donation quantities for human and livestock consumption such that retailer profit is maximized.

\subsubsection{Food Sharing Communities}

According to Food Tank (https: / / foodtank.com/, accessed on 13 January 2021) [60], there are several food sharing communities that are already in operation globally (for further details visit our arXiv paper [61].). Most of them use ICT in simple forms such as apps for volunteer organizations or social media for receivers to connect with the donors. With a more complex use of ICT, the communities can extend across borders, redistribute faster, communicate seamlessly, reach a wider audience, track food quality and movement, and exploit higher scalability, just to name a few.

\section{Materials and Methods}

The problem has been formally defined and a proposed mechanism as its solution has been suggested here. A schematic of the problem overview is presented in Figure 1. The donation that the donors make is transported by the volunteers, who are available on the fly or as planned, to the receivers for the matching assignment made by the algorithm. 
Notice that donors and receivers can also volunteer for transportation, while being a donor or a receiver, simultaneously.

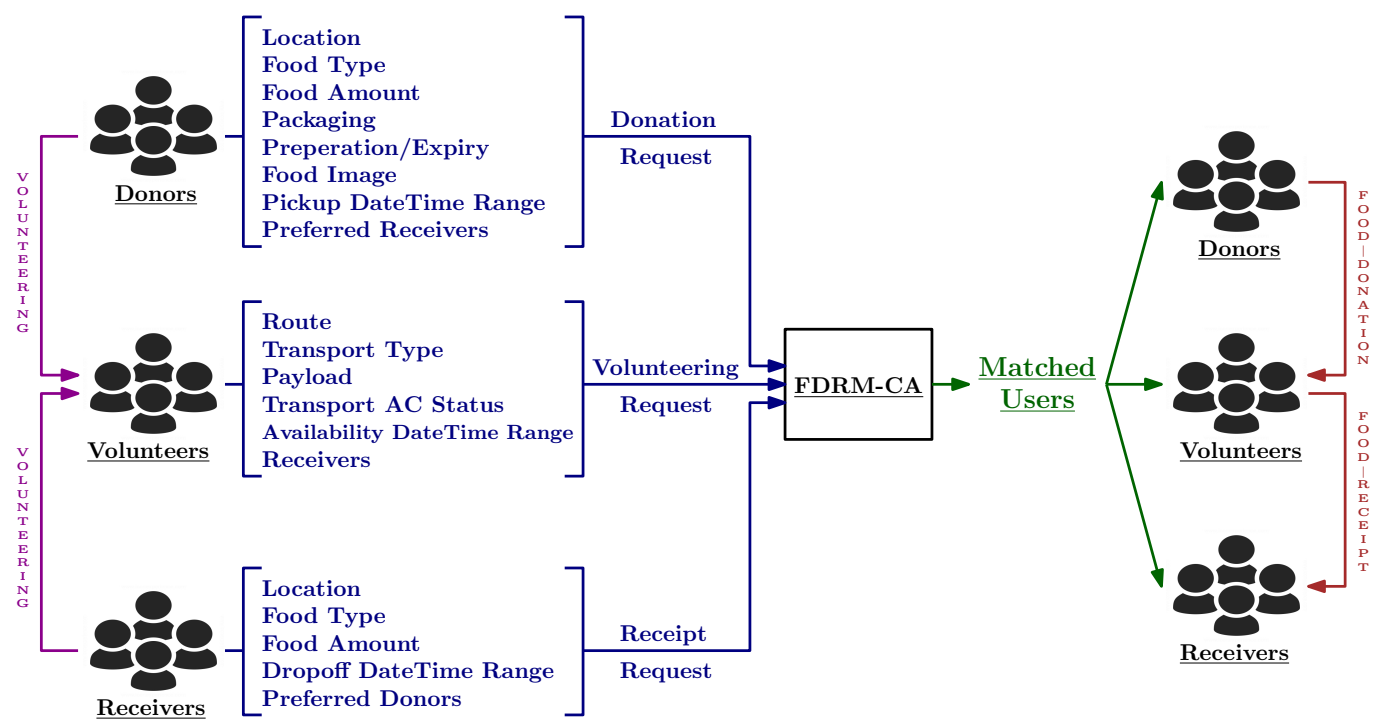

Figure 1. Overview of the model.

\subsection{Notations and Problem Formulation}

Our model has three types of agents: (1) the $d$ Donors, $\mathbb{D}=\left\{\mathbb{D}_{1}, \mathbb{D}_{2}, \ldots, \mathbb{D}_{d}\right\}$, (2) the $r$ Receivers, $\mathbb{R}=\left\{\mathbb{R}_{1}, \mathbb{R}_{2}, \ldots, \mathbb{R}_{r}\right\}$, (3) the $v$ Volunteers, $\mathbb{V}=\left\{\mathbb{V}_{1}, \mathbb{V}_{2}, \ldots, \mathbb{V}_{v}\right\}$. Here, agents represent their multiple food donation, requirement, and transportation requests. Certain lists will be holding data for comparison and classification. The lists $\mathbb{P}, \mathbb{C}, \mathbb{M}$ are for comparing perishable food items and storing unmatched and matched agent requests, respectively. Four lists bifurcate the food requests into Perishable $(\mathbb{P F D}$ for donors and $\mathbb{P F} \mathbb{R}$ for receivers) and Non-Perishable (NPFD for donors and $\mathbb{N P F R}$ for receivers) categories for prioritizing perishable food movement. The challenge here is to suggest a proper matching between these requests to execute this process with minimum manual intervention. The simplified process to achieve the same is shown in Figure 2. Certain thresholds used to tweak the system environment when required are:

- $\quad T_{0}$ minutes is the minimum overlap time between a donor and a volunteer for assignment;

- $T_{l} \%$ of their travel distance is what volunteers can manage in terms of going off their route to address requests;

- $T_{m}$ grams is the threshold meal size;

- $T_{a} \%$ of the extra donation weight required for volunteers for the smooth transportation of the donation;

- $\quad T_{P}^{n m}$ and $T_{P}^{m}$ kilometers are the threshold distances that perishable food can travel for without spoiling without $\mathrm{AC}$ in motored and non-motored transportation, respectively;

- $\quad T_{N P}$ kilometers is the threshold distance for non-perishable food to travel in a non-motored transportation;

- $\quad T_{d}$ and $T_{r}$ minutes are the threshold times before the start and end timings for donation, respectively, during which the request is considered available for matching;

- $\quad T_{w}$ minutes is the threshold beyond which unaccepted matches are auto-rejected. 


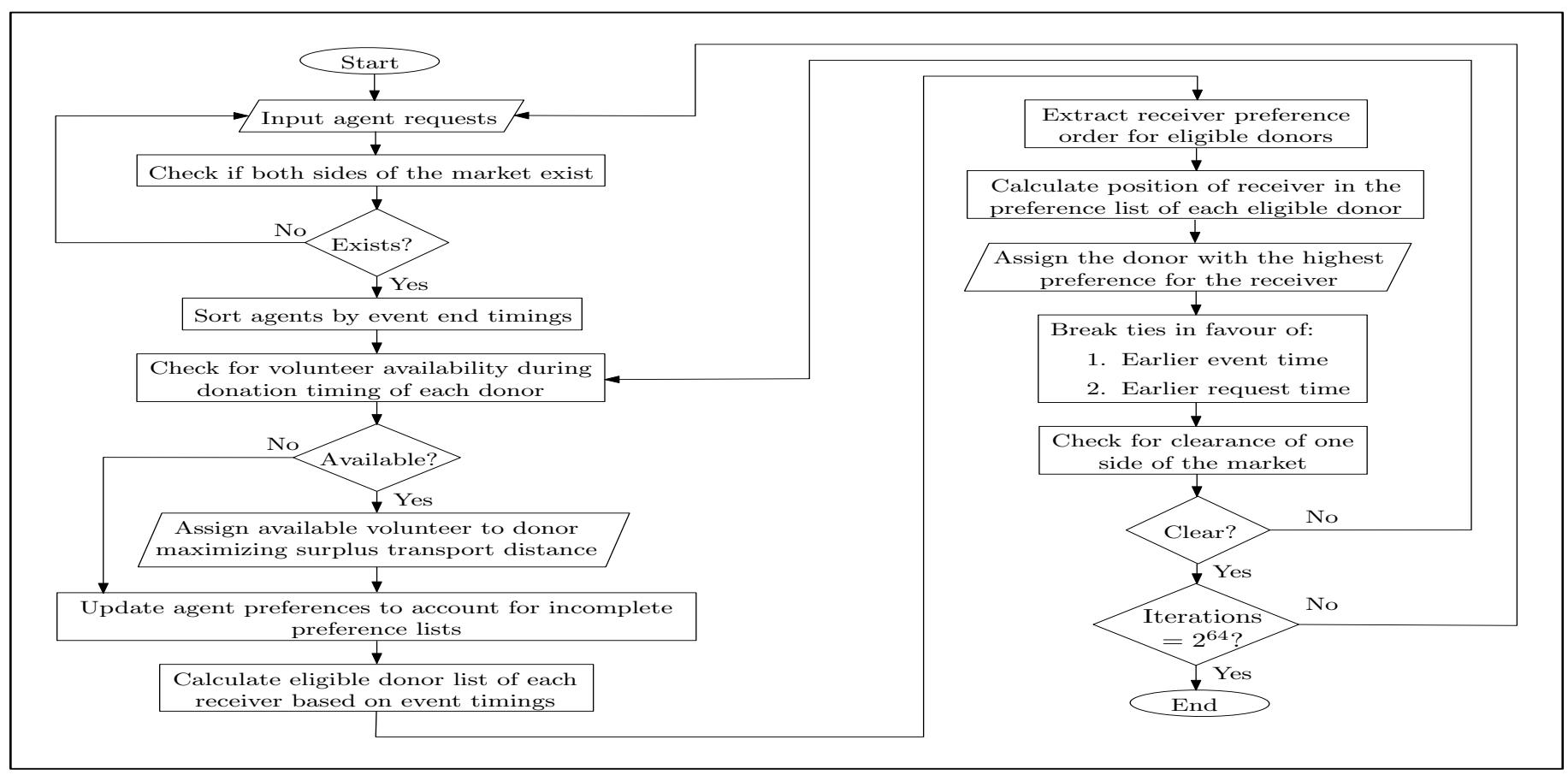

Figure 2. Process flow.

The agent details extracted for the matching process are as mentioned in Table 1. All requests are queued firstly into $\mathbb{C}$, and then classified into $\mathbb{V}, \mathbb{P F D}, \mathbb{N P F}, \mathbb{P F}$, and $\mathbb{N P F}$, as in Table 2. Matching of food items is carried out internally in these groups. An additional volunteer group $\mathbb{V}$, which is involved in the transportation of both perishable and non-perishable food items, is also present to classify the volunteer requests. Volunteer assignment for each donation request is carried out $T_{d}$ minutes before donation and with donor-volunteer pairs having at least $T_{0}$ minutes of availability overlap to account for real-time delays, as shown in Figure 3. Similarly, receivers are considered for matching $T_{r}$ minutes before their requirement start time. Now say we are tracking the $l$ th meal of the $k$ th food type donated by the $i$ th donor from the $j$ th location. Let this be our virtual donor $\mathbb{D}_{i j k l}$.

Table 1. Variables extracted for processing.

\begin{tabular}{|c|c|c|}
\hline Donors & Receivers & Volunteers \\
\hline Location & Location & Route \\
\hline Type of food to donate & Type of food required & Type of transport (motored or not) \\
\hline Amount of food to donate & Amount of food required & Payload capacity \\
\hline- & - & Air-conditioning status of the transport \\
\hline Pickup date and time range & Requirement date and time range & Availability date and time range \\
\hline Preferred receivers, if any & Preferred donors, if any & Receivers, if any \\
\hline
\end{tabular}

Table 2. Bifurcation of food requests.

\begin{tabular}{|c|c|c|c|}
\hline \multicolumn{4}{|c|}{ All Food Requests } \\
\hline \multicolumn{2}{|c|}{ Perishable } & \multicolumn{2}{|c|}{ Non-Perishable } \\
\hline Donations & Receipts & Donations & Receipts \\
\hline $\begin{array}{l}\text { The Perishable Food Donors } \\
\qquad(\mathbb{P F D})\end{array}$ & $\begin{array}{c}\text { The Perishable Food Receivers } \\
\text { (P्FR) }\end{array}$ & $\begin{array}{c}\text { The Non-Perishable Food } \\
\text { Donors }(\mathbb{N P F D})\end{array}$ & $\begin{array}{c}\text { The Non-Perishable Food } \\
\text { Receivers }(\mathbb{N P F})\end{array}$ \\
\hline
\end{tabular}




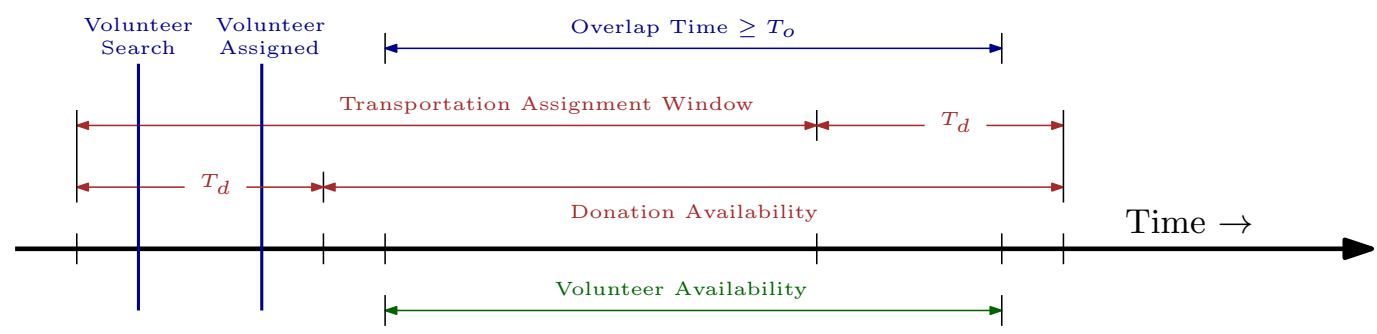

Figure 3. Volunteer assignment chronology.

For this donor, we selected those volunteers who have $\mathbb{D}_{i j k l}$ in a radius of $T_{l} \%$ of their travel distance, from their start location. The volunteer $\mathbb{V}_{m}$ who maximizes the distance (Vicinity) to which this donation $\mathbb{D}_{i j k l}$ can be transported is chosen, as in Figure 4. Volunteers are only considered if the payload capacity of the volunteer is $T_{a} \%$ more than the donation weight of $\mathbb{D}_{i j k l}$. The AC status of the transportation and whether the vehicle is motored or not are also factors in choosing the volunteer. This determines how far the surplus can be sent for consumption before it spoils. In case we did not have any volunteer to assign to this donor, we would still proceed to the receiver assignment process bypassing the volunteer assignment step. However, in that case, the Vicinity would be scaled down to its lower bound $\left(T_{P}^{n m} / T_{P}^{m} / T_{N P}\right)$ for the type of food being donated and whether the transport is motored or not, to make the transportation feasible for the agents. If the agents can predict volunteer unavailability in advance, they can themselves submit a volunteering request, in parallel, to aid the transportation themselves. This volunteering request then needs to have the receiver as its only entry in the volunteer's receiver list.

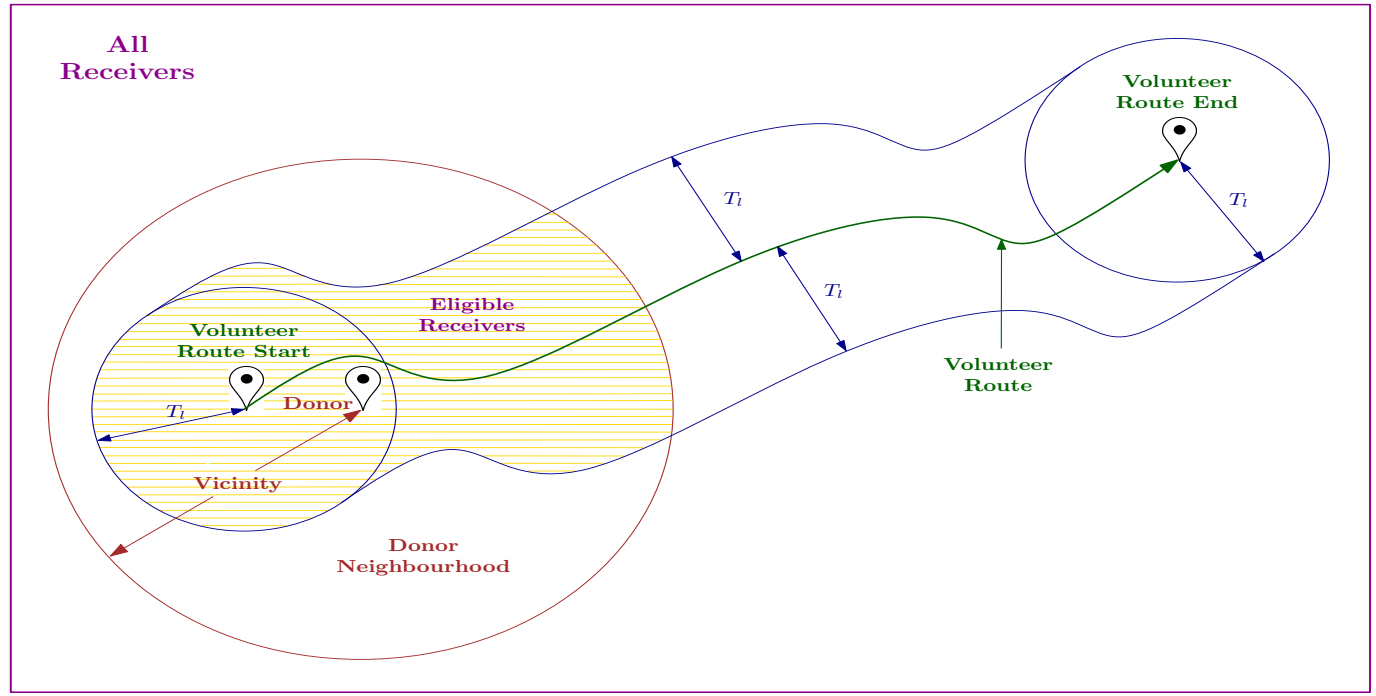

Figure 4. Receiver eligibility through priority modification.

The above volunteer assignment process considers certain important aspects while maximizing the surplus transport distance. Firstly, to ensure proper food safety while handling food (by donors, volunteers, receivers, etc.), only food donations with proper food packaging will be accepted for further distribution. This is upheld by the mandatory packaging selection option provided in the application platform. Secondly, the calculation of donor Vicinity, the maximum allowable distance between the donor and the receiver, ensures proper food preservation while in transit. The mechanism estimates a conservative distance for which the surplus can travel without spoiling. It uses input information such as the type of food, packaging, food preparation time for cooked food, food expiry date for packaged ones, food donation time range, Volunteer vehicle type, and vehicle air-conditioning status, whether the vehicle is motored or not, as seen in Figure 1, to calculate a time-span suitable for ensuring high food recoverability, which in turn dictates a conservative maximum distance 
(Vicinity) to which the surplus can be transported while ensuring food safety. The volunteer parameters that maximize this Vicinity are assigned for the transportation of this donation.

We now have our volunteer $\mathbb{V}_{m}$ assigned to the virtual donor $\mathbb{D}_{i j k l}$ and ready for receiver assignment. Let us now observe Figure 5, wherein one donor wants to donate two meals and two receivers want to receive one meal each. We assume volunteer availability for these donations. The two receivers have timings such that the donation is available before their requirement start times. However, the receiver with a later requirement start time $\left(\mathbb{R}_{2}\right)$ has very short availability. We can now address requirement requests starting with the earliest requirement start time or the earliest requirement end time. Assuming that we start with the earliest requirement start time, by the time the volunteer delivers a meal to $\mathbb{R}_{1}$ who has the earlier requirement start time, $\mathbb{R}_{2}$ 's requirement might end. Instead, if we start addressing the requirement requests starting with the earliest requirement end time, we can cater to the request of $\mathbb{R}_{2}$ first, followed by $\mathbb{R}_{1}$ who has a longer request availability time, thereby attending to both the receivers. Thus, we opt for addressing the requirements in an earliest end time first fashion.

As mentioned, whether donors have volunteers assigned or not, receivers are assigned anyway. Therefore, the priority order of the eligible donors, who donate before requirement start time, is extracted from the receiver's preference list, as in Figure 6. For donors not in the receiver's priority list, they are each assigned the minimum priority, as in Table 3, for receiver $\mathbb{R}_{n}$. This list is further filtered to have the eligible receivers selected from the donor neighbourhood and $T_{l} \%$ of the route distance away from the assigned volunteer's route as in Figure 4. Let us now get back to our virtual donor $\mathbb{D}_{i j k l}$ to whom volunteer $\mathbb{V}_{m}$ was assigned and was ready for receiver assignment. We now start the process from the receivers' end and reach this donor of ours as a match. Let, for tracking purposes, our donor $\mathbb{D}_{i j k l}$ be matched to the receiver $\mathbb{R}_{n}$. Then, $\mathbb{R}_{n}$ surely has $\mathbb{D}_{i j k l}$ in its extracted and augmented preference list. However, to be matched to each other, $\mathbb{D}_{i j k l}$ also needs to have the highest preference for $\mathbb{R}_{n}$, compared to all other eligible donors for this receiver, in its updated preference list. This list was prepared similar to what was carried out for the receiver preference, from the donor's submitted preference list and the receivers in the donor's neighbourhood determined by the calculated Vicinity, as in Table 3. When matching, ties are broken in favour of the earliest request submit time. Finally, the donation is picked up and delivered by the volunteer, as in Figure 7.

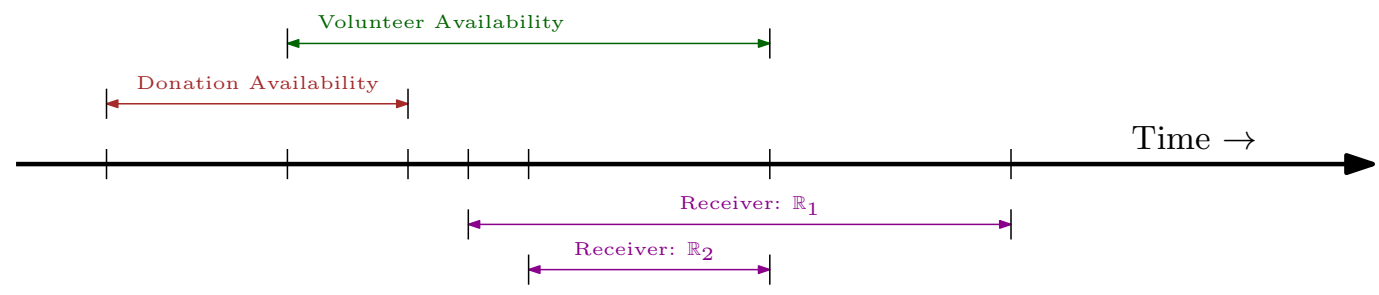

Figure 5. End time-based sorting for receivers.

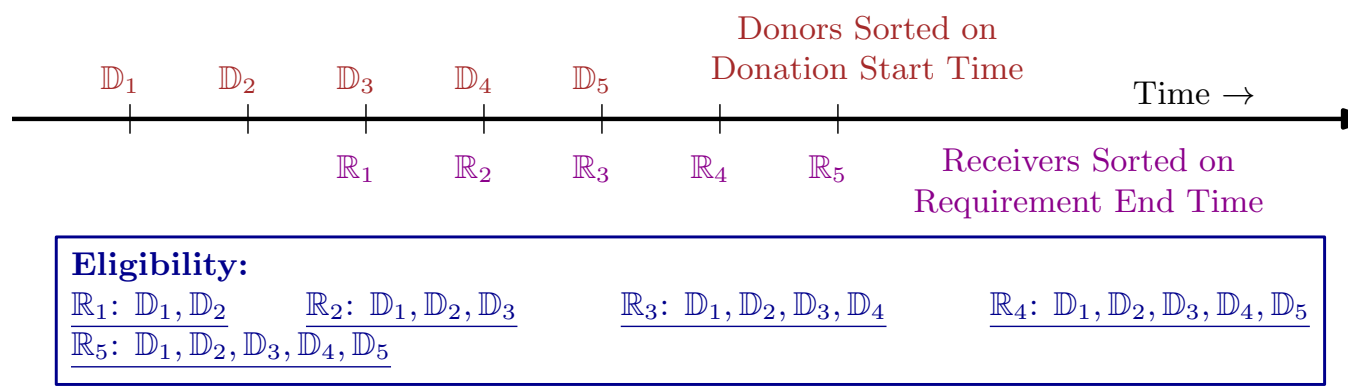

Figure 6. Donor eligibility per receiver. 
Table 3. Donor to receiver assignment.

\begin{tabular}{lll}
\hline \multicolumn{4}{c}{ Donor Preferences } \\
\hline $\mathbb{D}_{p}: \mathbb{R}_{1} \succ \mathbb{R}_{2} \succ \mathbb{R}_{3} \succ \mathbb{R}_{4} \succ \mathbb{R}_{n} \succ .$. & $\mathbb{D}_{q}: \mathbb{R}_{1} \succ \mathbb{R}_{n} \succ \mathbb{R}_{3} \succ \mathbb{R}_{4} \succ \mathbb{R}_{5} \succ .$. \\
$\mathbb{D}_{r}: \mathbb{R}_{1} \succ \mathbb{R}_{n} \succ \mathbb{R}_{3} \succ \mathbb{R}_{4} \succ \mathbb{R}_{5} \succ .$. & $\mathbb{D}_{s}: \mathbb{R}_{1} \succ \mathbb{R}_{2} \succ \mathbb{R}_{3} \succ \mathbb{R}_{n} \succ \mathbb{R}_{5} \succ .$. \\
\hline Original Preference & Eligibility List & Extraction \\
\hline $\mathbb{R}_{n}: \mathbb{D}_{q} \succ \mathbb{D}_{t} \succ \mathbb{D}_{p}$ & $\underline{\mathbb{R}_{n}: \mathbb{D}_{p}, \mathbb{D}_{q}, \mathbb{D}_{r}, \mathbb{D}_{s}}$ & $\underline{\mathbb{R}_{n}: \mathbb{D}_{q} \succ \mathbb{D}_{p}}$ \\
\hline Updated Preference & Preference Positions & Best Match \\
\hline $\mathbb{R}_{n}: \mathbb{D}_{q} \succ \mathbb{D}_{p}\left[\succ \mathbb{D}_{r}=\mathbb{D}_{s}\right]$ & $\underline{\mathbb{R}_{n}: \mathbb{D}_{p} .5, \mathbb{D}_{q} .2, \mathbb{D}_{r} .2, \mathbb{D}_{s} .4}$ & $\mathbb{R}_{n} \Longleftrightarrow \mathbb{D}_{q}$ \\
\hline
\end{tabular}

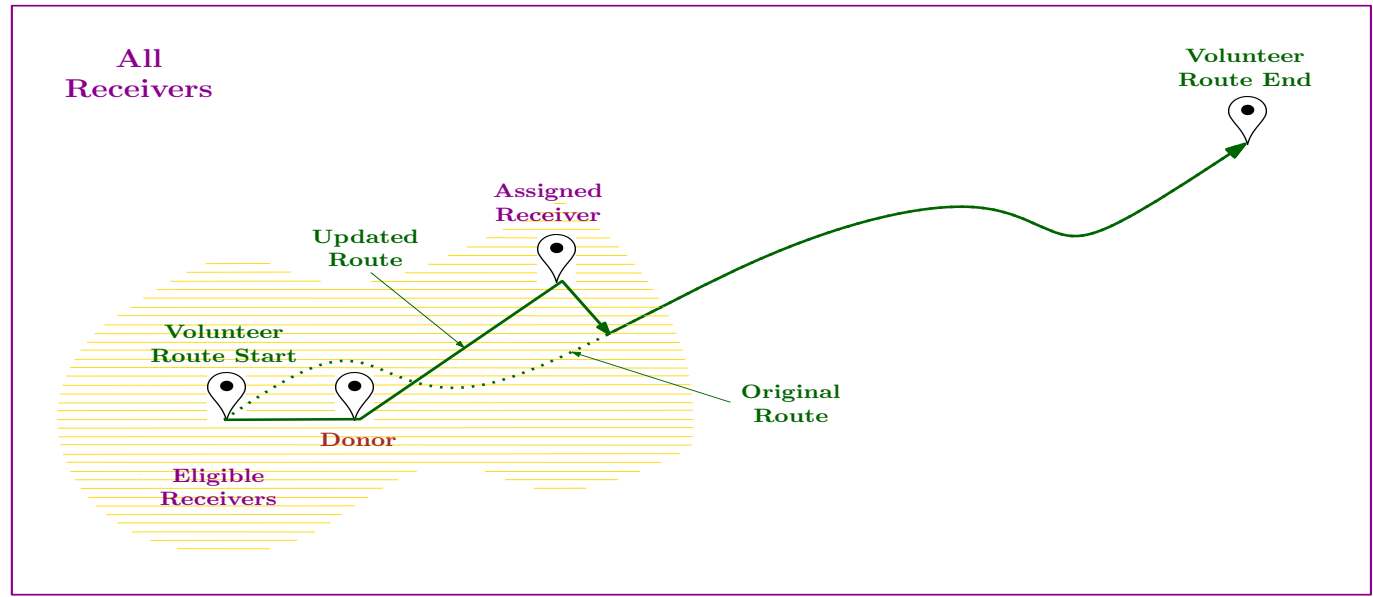

Figure 7. Food movement through volunteer.

\subsection{Proposed Mechanism}

The Food Donor to Receiver Matching with Chronological Acceptance (FDRM-CA) mechanism is proposed for matching donors to receivers, if possible, via volunteers.

\subsubsection{The FDRM-CA Mechanism}

The FDRM-CA mechanism actuates itself via the following steps:

1. Constant and parallel check for unaddressed agent requests using the New User Interrupt Routine (NUIR);

2. Classification and TriFurcation of Users (CTFU) into Perishable, Non-Perishable, and Volunteer categories;

3. Chronological Acceptance, inspired by [62,63], using Double Tie Breaking (CA-DTB) and on-the-fly preference updates, for the donor-receiver matching.

In Algorithm 1, right after initializing all the lists (line 1), the NUIR sub-process starts (line 3) to queue all unmatched agent requests. While this process continues in parallel, the queued agent requests are classified into perishable, non-perishable and volunteer groups (line 6), to match perishable food before the non-perishable ones. This is followed by matching donors with receivers, if possible, via volunteers (lines 7 and 10), taking into consideration agent preferences. Each match is then displayed to the involved agents (lines 9 and 12). All unmatched agent requests are considered in the upcoming iterations. 


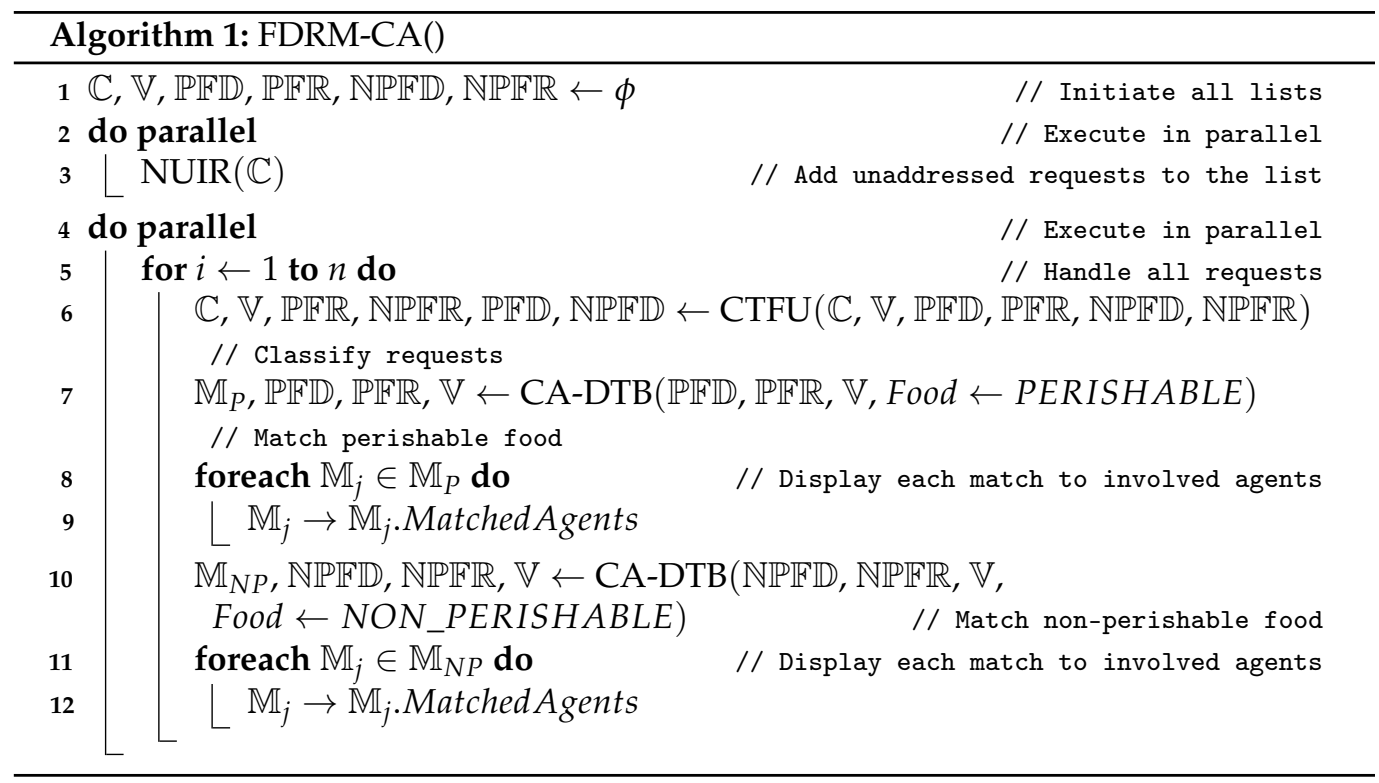

\subsubsection{The NUIR Sub-Process}

The NUIR sub-process (Algorithm 2) runs in parallel with the main mechanism without halting it. Here, at each agent request submission, the NewUserRequestInterrupt interrupt is generated that triggers this routine to split the request into multiple meal requests and add them to the list of unaddressed agent requests (lines 4 to 7 ). Additionally, when any involved agent rejects or does not accept a match in $T_{w}$ minutes of match generation by, the interrupt MappingRejectionInterrupt is generated that triggers this routine to add all of the involved agent requests of this rejected match to the aforementioned list (lines 8 to 10) for being considered in the next iteration of the mechanism.

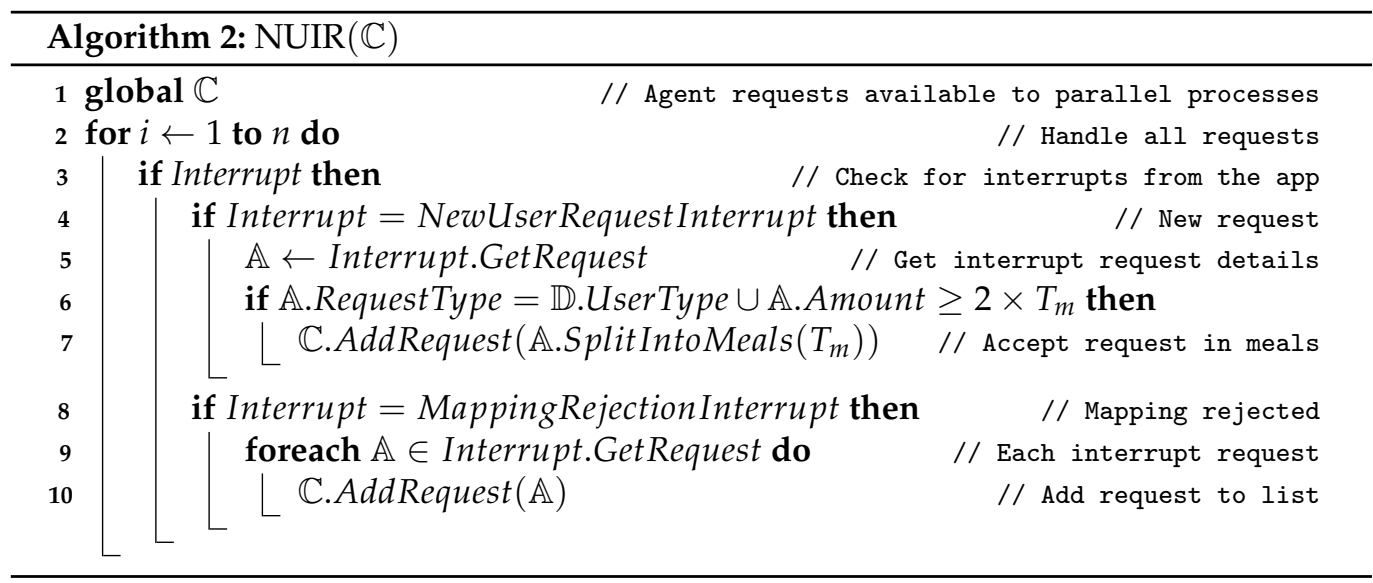

\subsubsection{The CTFU Sub-Process}

The CTFU sub-process (Algorithm 3) classifies the agent requests into either volunteers, or perishable/non-perishable categories for donors/receivers (lines 2 to 10) to facilitate perishable food matching before the non-perishable ones. 


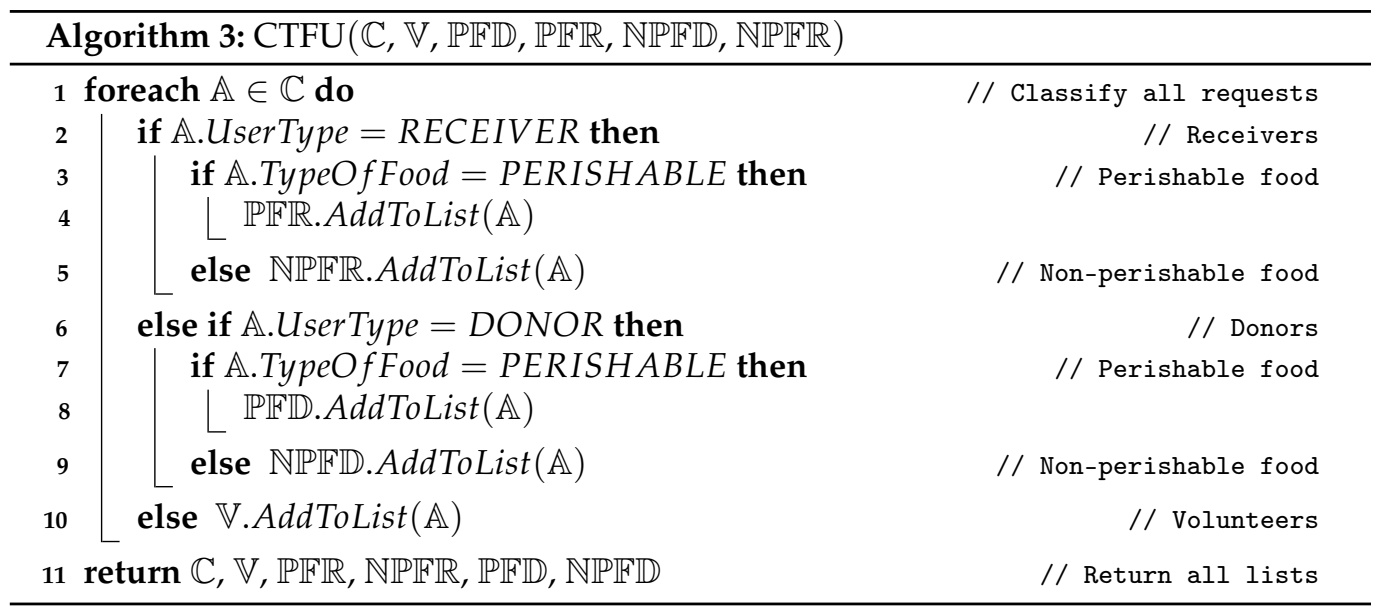

\subsubsection{The CA-DTB Sub-Process}

The algorithm for the CA-DTB sub-process is as follows.

The CA-DTB sub-process (Algorithm 4) gathers current agent requests (lines 2 and 3), and assigns volunteers, if available, to each donor $\mathbb{D}_{i}$ (line 5 ), maximizing the surplus transportation distance (lines 10 and 20). Next, agent preferences are updated by extraction and augmentation as shown in Table 3 (line 23 to 25). After this, each receiver $\mathbb{R}_{i}$ is assigned to the eligible donor who has the highest preference for $\mathbb{R}_{i}$ (lines 26 to 31), and the match is stored in $\mathbb{M}$. Receivers accept donations such that:

$$
\sum_{j=1}^{m} \mathbb{D}_{j} \text {. Amount }-\epsilon=\mathbb{R}_{i} \text {. Amount } ; \epsilon \rightarrow 0 .
$$

This step is repeated until one side of the market is cleared. Ties are broken first with food donation start/requirement end timings (duplicates allowed), and next with request arrival timings (total order maintaining sequences without duplicates). All matched requests have to be accepted by the involved agents in a time window of $T_{w}$ minutes, beyond which the match is automatically rejected and the requests involved are automatically lined up for the next round of matching. 


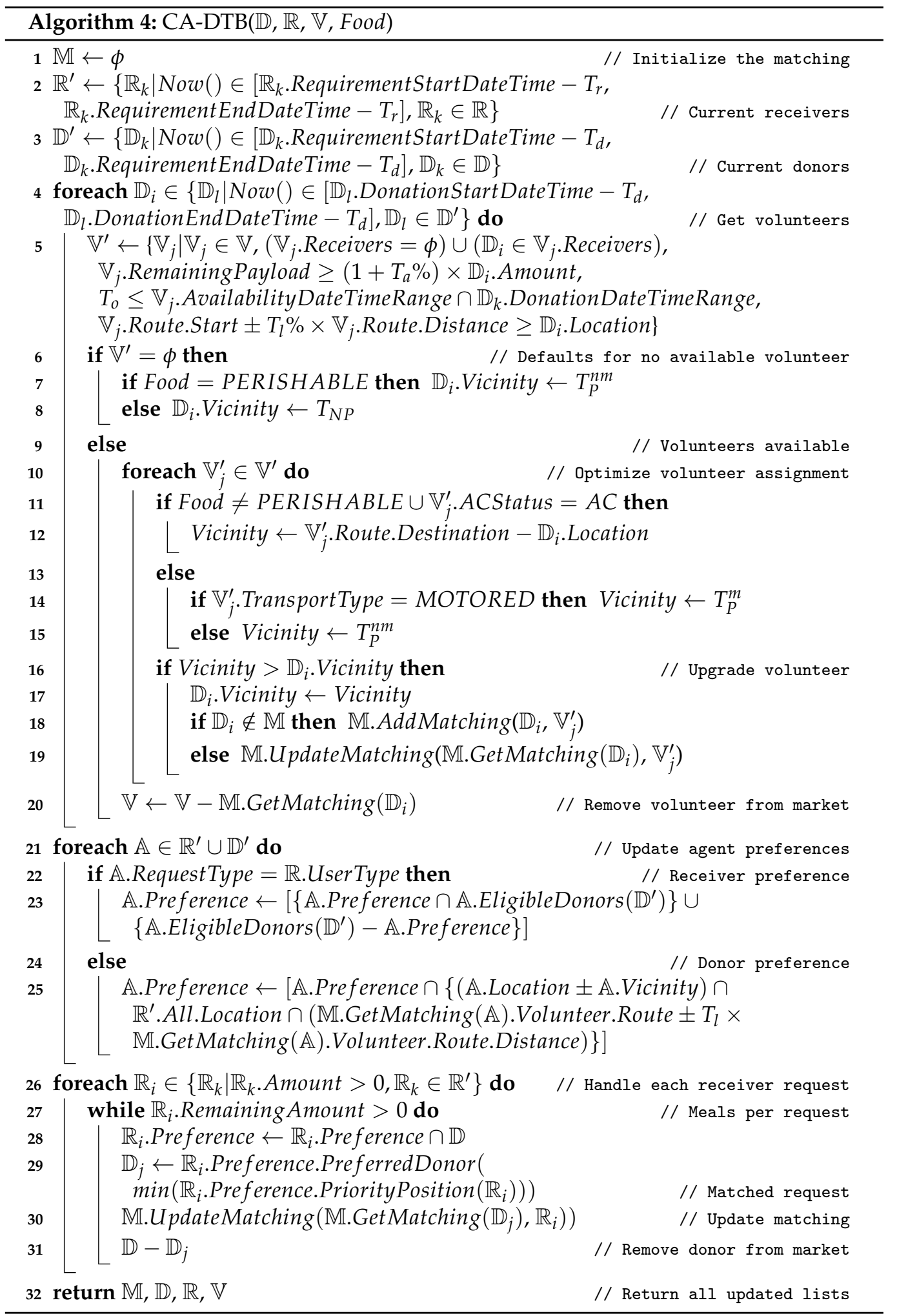

\section{Algorithm Analysis}

In this section, we discuss the correctness, strategyproofness, Pareto-optimality, real-time operation and practicality properties of the FDRM-CA algorithm.

\subsection{Correctness}

Lemma 1. FDRM-CA works correctly. 
Proof. We prove this using the loop invariant technique [64]. We start our proof with the main FDRM-CA algorithm and then we detail the inner sub-processes.

Algorithm 1 (The FDRM-CA Mechanism): here, we use the following loop invariant:

At the start of the $i$ th iteration of the for loop of lines 5-13, each receiver $\mathbb{R}_{j}$ processed in the prior $(i-1)$ iterations have their best available donors allocated, respecting the eligible donors' preference lists.

Initialization: prior to the first iteration of the loop, $i=1$, there are no receivers processed and no matching exists. This trivially satisfies the invariant.

Maintenance: At any iteration $i$ of the loop, each receiver $\mathbb{R}_{j}$ processed is classified into either perishable or non-perishable category. Thereafter, for each donor in the priority list of $\mathbb{R}_{j}$, the donor's ranking of $\mathbb{R}_{j}$ is retrieved. The donor $\mathbb{D}_{k}$ with the highest ranking for $\mathbb{R}_{j}$ is assigned to $\mathbb{R}_{j}$. Furthermore, $i$ is used for the next iteration of the for loop maintains the invariant.

Of course, the correctness of the above step depends on the correctness of the inner sub-parts, which is proven later in this section.

Termination: At termination, when $i=n+1$, each receiver $\mathbb{R}_{j}$ processed in the prior $n$ iterations has the best available donors allocated, respecting the eligible donors' preference lists. This proves that the FDRM-CA algorithm works correctly.

To reinforce the maintenance step of this proof, following are the additional proofs of correctness of the sub-processes of this algorithm.

Algorithm 2 (The NUIR Sub-Process): This can be proved along similar lines as above and is included in Appendix A.

Algorithm 3 (The CTFU Sub-Process): Here, we use the following loop invariant:

At the start of the $i$ th iteration of the foreach loop of lines 1-13, the first $(i-1)$ agent requests from $\mathbb{C}$, processed in the prior $(i-1)$ iterations, have been classified and appended to one of the five lists, namely, $\mathbb{V}, \mathbb{P F D}, \mathbb{N P F D}, \mathbb{P F R}, \mathbb{N P F R}$.

Initialization: Prior to the first iteration of the foreach loop, there are no agent requests processed, and this trivially satisfies the invariant.

Maintenance: In the $i$ th iteration, the $i$ th agent request is taken up for processing from the list $\mathbb{C}$. If this agent request is a volunteer request, it is appended to the list $\mathbb{V}$. If not, it is classified and appended to one of the four food request lists, namely, $\mathbb{P F D}$, $\mathbb{N P F} \mathbb{D}, \mathbb{P F} \mathbb{R}$, and $\mathbb{N P F R}$. Observe that, prior to this iteration, all the five lists, namely, $\mathbb{V}, \mathbb{P F D}, \mathbb{N P F D}, \mathbb{P F} \mathbb{R}, \mathbb{N P F R}$, already had a total of $(i-1)$ agent requests from $\mathbb{C}$ classified and appended to them from the $(i-1)$ prior iterations. As the foreach loop picks up the next agent request from $\mathbb{C}$ for the next iteration, the loop invariant is re-established.

Termination: At termination, the list $\mathbb{C}$ is empty and all agent requests have been classified and appended to one of the five lists, namely, $\mathbb{V}, \mathbb{P F D}, \mathbb{N P F D}, \mathbb{P F}, \mathbb{R} P \mathbb{R}$. Thus, the invariant is maintained. This proves that the CTFU process works correctly.

Algorithm 4 (The CA-DTB Sub-Process): This can be proved along similar lines as above and is included in Appendix A.

By having proven the correctness of all its sub-parts, this concludes our proof of correctness of the FDRM-CA mechanism.

\subsection{Strategyproofness}

Lemma 2. FDRM-CA is strategyproof for donors and receivers.

Proof. While there can be many places in FDRM-CA for donors to misreport, they can never gain from the same location. Firstly, say a donor $\mathbb{D}_{i}$ misreports the donor's preference list as $\mathbb{R}_{k} \succ \mathbb{R}_{j}$. Since the CA-DTB method awards the best available option from this preference list, misreporting only gains the donor $\mathbb{D}_{i}$ and the option $\mathbb{R}_{k}$. The only way a donor $\mathbb{D}_{i}$ can gain is if $\mathbb{R}_{k}$ becomes unavailable in the extracted and updated preference list of $\mathbb{D}_{i}$. However, that is a run-time phenomenon not affected by the preference list of the donor, and hence not affected by manipulation. The above line of thinking can be extended to 
other input details of the donors such as location and type of food. Note that misreporting the amount of food donated by $\mathbb{D}_{i}$ does not affect the order in which receivers are chosen for matching, it only changes the count of receivers assigned to the donor $\mathbb{D}_{i}$. Secondly, donors cannot influence the choice of their neighbourhood as it depends on the run-time availability of volunteers $(\mathbb{V})$ and the details of their transport. Thirdly, ties are broken primarily in favour of the earliest food donation or requirement timings, which can be misreported. Consider a donor $\mathbb{D}_{i}$ who misreported food pickup time to a time $\left(t_{a}\right)$ before the food is available for pickup $\left(t_{b} ; t_{a}<t_{b}\right)$. Since, food pickup is a volunteer-mediated activity and volunteers only have a window of time available, the availability of a volunteer $\mathbb{V}_{j}$ at a misreported time $\left(t_{a}\right)$ does not guarantee the donor the availability of any volunteer at the donor's truthful pickup time $\left(t_{b}\right)$. Worst case scenario, no volunteers may be available at the truthful pickup time $\left(t_{b}\right)$. This concludes the proof. The study can prove, along similar lines, that FDRM-CA is strategyproof for receivers as well.

\subsection{Pareto-Optimality}

Lemma 3. FDRM-CA is Pareto-optimal for donors.

Proof. This we prove by contradiction and mathematical induction. Let us assume that FDRM-CA is not Pareto-optimal. Additionally, let there be some other algorithm, say OTH, that assigns Pareto-optimality. The basis condition for induction is trivial for zero iterations. For the induction step, say until iteration $i$, both algorithms generate similar matchings $\mathbb{M}_{i}$. In the $(i+1)$ th iteration, the CA-DTB sub-process of the FDRM-CA mechanism assigns the best available option for donors as per their respective preference lists and updates the matching to $\mathbb{M}_{i+1}$. If OTH assigns anything other than the above, then it does not generate a Pareto-optimal matching $\left(\mathbb{M}_{i+1}\right)$ at this iteration. Therefore, by the Principle of Mathematical Induction, the final matching generated by OTH will also not be optimal. This is a direct contradiction to our initial assumption. Thus, we can say that our initial assumption was not correct and that FDRM-CA is Pareto-optimal for donors. This concludes the proof.

\subsection{Real-Time Operation}

Lemma 4. FDRM-CA produces results in real (polynomial) time.

Proof. We only analyzed the time complexity of a single iteration of the FDRM-CA mechanism since after each iteration agents receive their assignments. Since food is only recoverable inside a time window, we will focus our analysis from the donor point of view. For this, we analyzed the time complexity of each sub-process of the mechanism. Note that receivers with large requirements may acquire their complete matching (that is equal to their total requirement) after several iterations of the mechanism.

- The NUIR sub-process is parallel to the main process and thus does not have any impact on the time complexity as it does not need to finish for the main process to execute;

- $\quad$ The CTFU sub-process takes $\mathrm{O}(d+r+v)<\mathrm{O}\left(r^{2}\right)$;

- The CA-DTB sub-process can be viewed as having two sub-parts:

- The sub-part to determine the neighbourhood of each donor and volunteer assignment to the donor takes $\mathrm{O}(d v)<\mathrm{O}\left(r^{3}\right)$;

- The update of preference and match generation sub-part has a time complexity of $\mathrm{O}\left(d^{2} r\right)<\mathrm{O}\left(r^{3}\right)$, since $r>d$ for most practical situations, especially in developing countries such as India, at the time of writing this paper.

where $d, r$, and $v$ are the numbers of donors, receivers, and volunteers, respectively, per iteration of the FDRM-CA mechanism. Therefore, the effective time complexity of each iteration of the FDRM-CA mechanism is capped at $\mathrm{O}\left(r^{3}\right)$, which is a polynomial (real) time. This concludes the proof. 


\subsection{Practicality}

Lemma 5. Using an off routing threshold $T_{l} \%$, the maximum total off-routing percentage $(\Gamma)$ for any volunteer for each meal transportation will always be less than equal to four times this threshold percent of the route distance of the corresponding volunteer, i.e., $\Gamma \leq 4 \times T_{l}$.

Proof. Analyzing a worst case scenario, let the donor $\mathbb{D}_{i}$ 's location be opposite to the volunteer $\mathbb{V}_{j}$ 's route, and at a maximum possible distance of $T_{l} \%$ of the volunteer's travel distance. Therefore, the donation pickup will contribute to an extra travel distance of $2 \times T_{l} \%$ for the volunteer. Assuming a similar situation at the drop-off end yields another $2 \times T_{l} \%$ travel overhead for the volunteer $\mathbb{V}_{j}$. Thus, even in the worst case scenario, the volunteer $\mathbb{V}_{j}$ has to do a maximum total off-routing percentage given by the inequality $\Gamma \leq 4 \times T_{l}$. This concludes the proof for the practical nature of the algorithm.

\section{Results}

Figure 8 presents the simulation results of the mechanism. In all the graphs, volunteer numbers have been expressed in terms of multiples of donation numbers $(\times$ Donors $)$. Other than their relevant results, end sorting for receivers and updated preferences for all agents have been used.

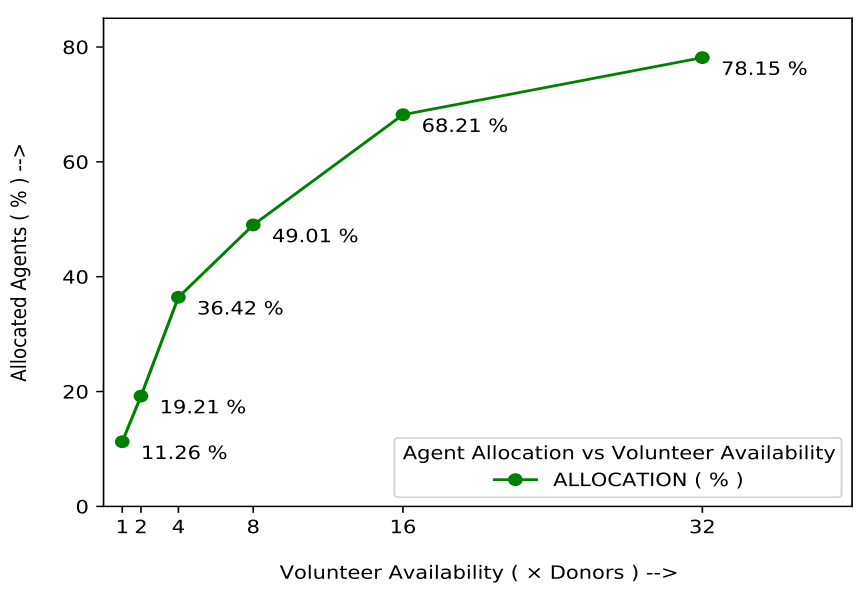

(a) Allocation vs. Volunteer Availability

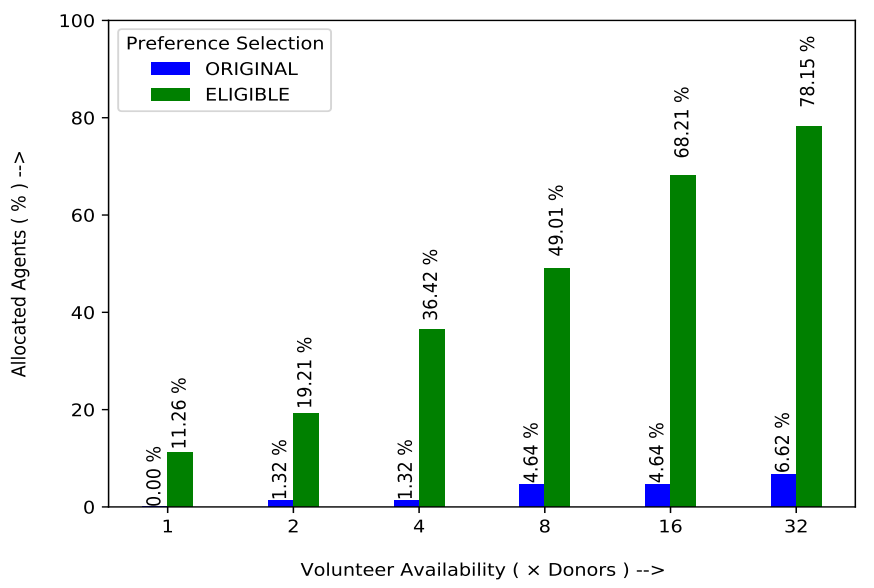

(c) Original vs. Eligible Preferences

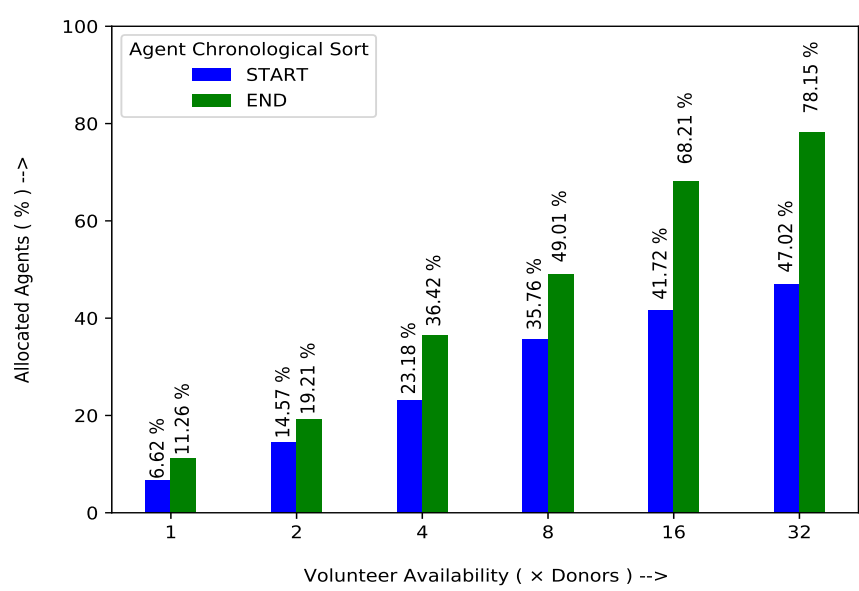

(b) Start vs. End Sorting for Receivers

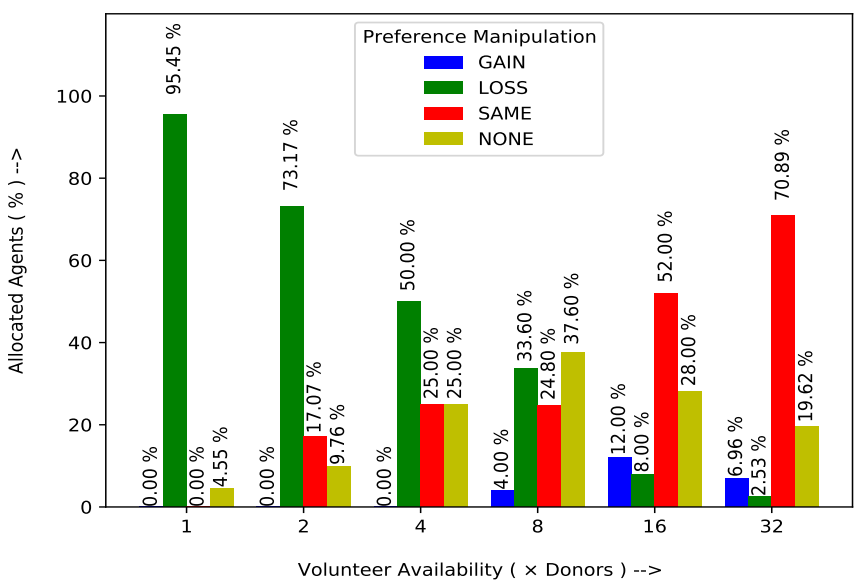

(d) Preference Manipulation Results

Figure 8. Simulation results. 


\subsection{Data}

We generated random, logically coherent data for 5000 agent requests and chose our operational city to be $50 \times 50 \mathrm{~km}$ across, our working hours to be from $06: 00 \mathrm{~h}$ to $23: 59 \mathrm{~h}$, and any volunteer's maximum payload capacity to be $100 \mathrm{~kg}$. We have taken our threshold values as: $T_{o}=15 \mathrm{~min}, T_{d}=120 \mathrm{~min}, T_{r}=180 \mathrm{~min}, T_{w}=10 \mathrm{~min}, T_{l}=5 \%, T_{a}=20 \%$, $T_{m}=1000 \mathrm{~g}, T_{P}^{m}=20 \mathrm{~km}, T_{P}^{n m}=5 \mathrm{~km}$, and $T_{N P}=100 \mathrm{~km}$.

\subsection{Analysis}

It is evident from Figure 8a that the allocation percentage of agents initially increases rapidly with increase in volunteer availability and then plateaus as the availability grows further. Figure $8 \mathrm{~b}$ shows that volunteers going for the receiver having the earliest requirement end time will be able to address more requests. Similarly, Figure $8 \mathrm{c}$ depicts the importance of updating the submitted agent preferences to reflect run-time temporal and spatial availability of agents. At last, Figure $8 \mathrm{~d}$ establishes that manipulation of preferences will not help agents to gain a better allocation other than when a small percentage of them do not have their false higher preferred donors available while calculating their eligibility lists.

\section{Discussion}

The results presented in Section 4 reveal and reinforce certain preferable policies to be followed by any such approach, in general, towards the matching of donors and receivers:

- The availability of volunteers matter: This is intuitive and clearly evident. As volunteer availability goes up, so does the number of matching sets. However, this happens relatively faster at the start followed by a plateau thereafter. Thus, a basic minimal availability of volunteers is required for the mechanism to produce good results.

- Receiver requirement end timings dictate the matching order: Although it seems quite counter-intuitive to address receiver requests that end first, it is very essential to do so. It is clearly evident that this receipt window is not the window in which the donated food is actually consumed. It is rather a food accumulation window right before the food consumption begins. Therefore, by satisfying the requirements whose accumulation windows are about to end, we are actually reach the requirement request whose food consumption window starts first. In terms of food utilization, this is most important.

- The dynamic nature of the market should be captured: While the agents provide their preferences with a static image of the market, it is very important to capture the dynamism of the same. Real-time situations such as unavailability of preferred agent requests and efficacy constraints such as distance limitations arising from the perishable nature of the donation can change the scenario quite a bit. By modifying the preference list of the agents to include the eligible options, the allocation, and thereby the utilization, of surplus food can be drastically improved.

- A regret-free platform for fair donation allocation: While it is a great facility to be able to provide preferences by agents, it can also be heavily abused. This flexibility that the mechanism provides has to be safeguarded from being over-utilized, leading to the deprivations of some agents from being mapped at all. To ensure that the provided preferences do not have an adverse effect on the mapping process, and that the same cannot be intentionally achieved by agents, provides a regret-free preference manipulation-independent platform for agents to utilize.

\section{Conclusions}

Surplus food distribution is visibly not a long term solution for food wastage, and the issue has to be tackled at the roots by putting a check on the inclination of the society towards a permanent over-supply of food and a fear of running-out of food. Additionally, in the upcoming smart cities, apart from several other factors, proper transportation and storage infrastructures at different stages of food production have a great impact 
on the sources and the amount of food wasted. However, until the society structure, leading to a permanent over-hoarding and wastage of food, is fixed, ICT-based surplus food distribution systems will continue to bridge the gap between the over-supplied and the under-provided. In the upcoming smart cities, there is a vast opening in which ICT platforms, especially handheld device-based apps, can prove pivotal in facilitating a smoother food redistribution by percolating deep into the masses of both urban and rural locations. Although $100 \%$ of the food waste cannot be targeted by this approach, the $60 \%$ avoidable waste will be diverted from landfills to the under-provided people.

The FDRM-CA mechanism, delivered by handheld device apps, provides a great platform for carrying this out specifically. It prevents donors from misreporting, addresses donor and receiver preferences properly, prioritizes food donation/requirement events chronologically, matches donors optimally with receivers and volunteers, and above all, achieves all this to provide agents with their respective assignments in real time, making it an attractive choice for the task. As receivers gradually broaden the spectrum of their requirements from the more common freshly cooked and packaged solid food types towards the statistically rarer fresh produce and frozen uncooked food types, and as donors are diversified from households to farmers and business people, this redistribution approach will be able to target the different stages of food production wherein food is wasted. With the use of double-sided market related game-theoretic algorithms for mapping, the preferences of all the parties can be addressed better, leading to a higher satisfaction of all the agents involved. This is guaranteed to attract more participation in the food redistribution network, eventually lowering the food wastage and hunger challenges of the world for a sustainable and scalable food future.

In the future, if some volunteers find incentives as their primary motivation to participate in the system, the same can be integrated with the model for a hybrid functionality so as to attract a broader volunteer participation, leading to an overall better surplus movement.

Author Contributions: Conceptualization, S.S., V.K.S., F.X., B.S. and S.M.; methodology, S.S., V.K.S., F.X., B.S. and S.M.; validation, S.S., B.S. and S.M.; formal analysis, S.S., V.K.S., B.S., F.X. and S.M.; investigation, S.M. and F.X.; writing-original draft preparation, S.S., V.K.S., F.X., B.S. and S.M.; writing-review and editing, S.S., V.K.S., F.X. and S.M.; supervision, F.X. and S.M. All authors have read and agreed to the published version of the manuscript.

Funding: This research received no external funding.

Informed Consent Statement: Not applicable.

Data Availability Statement: The data used in the simulation of the mechanism have been synthetically generated through Python libraries and the corresponding code is available in GitHub at https: / / github.com/Surja-Sanyal/Surplus-Food-Distribution-Simulation-2021-May.git, accessed on 4 May 2021. The code was also used to generate the simulation results and their corresponding graphs included in the paper. The parameters used, as stated in Section 4, are mentioned here as well.

Conflicts of Interest: The authors declare no conflict of interest.

\author{
Abbreviations \\ The following abbreviations are used in this manuscript: \\ ICT Information and Communications Technology \\ P2P Peer-to-Peer \\ FDRM-CA Food Donor to Receiver Matching with Chronological Acceptance \\ NUIR New User Interrupt Routine \\ CTFU Classification and TriFurcation of Users \\ CA-DTB Chronological Acceptance using Double Tie Breaking
}

Appendix A. Proofs Excluded from Section 3

Here we present the rest of the proof of correctness of the FDRM-CA algorithm. 
Lemma A1. FDRM-CA works correctly.

Proof. We use loop invariant techniques as mentioned before.

Algorithm 1 (The FDRM-CA Mechanism): This is already proven in Section 3.

Algorithm 2 (The NUIR Sub-Process): For this algorithm we use the following loop invariant:

The global list $\mathbb{C}$ has all agents with unaddressed requests.

Initialization: Prior to the first iteration of the loop, the list is empty, and trivially satisfies the invariant.

Maintenance: In the $i$ th iteration, one of the interrupts NewUserRequestInterrupt and MappingRejectionInterrupt is generated as a response to a new agent request or rejection of a mapping by its involved agent(s) respectively, due to which agent requests are added to this list. In case NewUserRequestInterrupt is generated, the new agent has raised a request in the app that is yet to be addressed. If a MappingRejectionInterrupt is generated, On the contrary, the agents involved in the rejected mapping have unfulfilled requests, and are again added to this list. Since, the list $\mathbb{C}$ had only agents with either active or unmatched requests before this iteration, therefore, it still has so. Thus, the loop invariant is maintained.

Termination: At termination, when $i \leftarrow n, n$ being a very large number, the list $\mathbb{C}$ now contains all agents with unaddressed requests. This proves that the NUIR process works correctly.

Algorithm 3 (The CTFU Sub-Process): This is already proven in Section 3.

Algorithm 4 (The CA-DTB Sub-Process): This algorithm has three sequential foreach loops.

1. For the first foreach loop we use the following loop invariant:

The matching $\mathbb{M}$ has donors, each donor with the donor's largest possible neighbourhood, as per volunteer availability, assigned to the donor.

Initialization: Prior to the first iteration of the loop, the list is empty, and that trivially satisfies the invariant.

Maintenance: In the $i$ th iteration, donor $\mathbb{D}_{i}$ is taken up for processing. A neighbourhood of volunteers is now calculated for the same. If this neighbourhood:

- Has no volunteer, then the best possible Vicinity, and therefore, neighbourhood, is assigned to the donor as per the type of food donation, and the donor is added to the list $\mathbb{M}$ before exiting this iteration.

- Has volunteers, then another loop is encountered for which we use the loop invariant:

The current donor receives the largest possible neighbourhood as per volunteer availability.

Initialization: Before entering this loop, the list $\mathbb{M}$ does not have the current donor. Therefore, it trivially satisfies the loop invariant.

Maintenance: In the $j$ th iteration, a new Vicinity is calculated using the type and air-conditioning status of the transport of the $j$ th volunteer and the type of food to be donated by the $i$ th donor. This Vicinity is updated for the donor only if it provides this donor with a larger neighbourhood than that of the already existing Vicinity value of this donor. Also, this $j$ th volunteer gets assigned to this $i$ th donor only if this current Vicinity is better, as just described, than that existing for this donor. Thus, each iteration only improves upon the existing volunteer allocation and the neighbourhood assigned to this donor, thereby maintaining the invariant.

Termination: At termination, the available volunteers' list $\left(\mathbb{V}^{\prime}\right)$ is exhausted and the $i$ th donor has already acquired the best possible volunteer, and therefore, neighbourhood, and is added to the list $\mathbb{M}$. Thus, this loop works as intended. 
Thus, the largest possible neighbourhood for this donor, as per volunteer availability, has been assigned to this donor. Thus, the invariant is maintained.

Termination: At termination, when all available donors have been processed, the list $\mathbb{M}$ has donors, each donor with the donor's largest possible neighbourhood, as per volunteer availability, assigned to the donor. This proves that this loop works properly.

2. For the second foreach loop we use the following loop invariant:

All agents in donors and receivers acquire updated preferences.

Initialization: Prior to the first iteration of the loop, agent preference is not updated and that trivially satisfies the invariant.

Maintenance: In the $i$ th iteration, the $i$ th agent is taken up for processing. This agent is recognized one of donors and receivers and the preference is updated accordingly. Thus, the invariant is maintained.

Termination: At termination, All the agents in donors and receivers have been processed and all of them have their preferences updated. This satisfies the invariant. Therefore, the correctness of the second foreach loop is proved.

3. For the third sequential foreach loop, we use the following loop invariant:

Donors are assigned to receivers such that they fulfill their meal requirements and both donor and receiver preferences are considered.

Initialization: Prior to the first iteration of the loop, no donors are assigned to receivers and that trivially satisfies the invariant.

Maintenance: This is a nested foreach loop construct with two such loops in the nest. For any receiver $R_{i}$, donors are assigned to it until the required meals are fulfilled. Additionally, receivers acquire their preferences in case of ties and donors have their neighbourhood predefined to address their preferences. Thus, the loop invariant is maintained.

Termination: At termination, all donors have already been assigned the best available receivers as per the preferences of the donors and the receivers. Therefore, the invariant is upheld. This proves the correctness of the last foreach loop of the CADTB process.

By having proven the correctness of all its sub-parts, this concludes our proof of correctness of the FDRM-CA mechanism.

\section{References}

1. Ganglbauer, E.; Fitzpatrick, G.; Molzer, G. Creating visibility: Understanding the design space for food waste. In Proceedings of the 11th International Conference on Mobile and Ubiquitous Multimedia, Ulm, Germany, 4-6 December 2012; pp. 1-10.

2. Harvey, J.; Smith, A.; Goulding, J.; Illodo, I.B. Food sharing, redistribution, and waste reduction via mobile applications: A social network analysis. Ind. Mark. Manag. 2020, 88, 437-448. [CrossRef]

3. Shi, Z.R.; Yuan, Y.; Lo, K.; Lizarondo, L.; Fang, F. Improving Efficiency of Volunteer-Based Food Rescue Operations. In Proceedings of the AAAI, New York, NY, USA, 7-12 February 2020; pp. 13369-13375.

4. Zhong, R.; Xu, X.; Wang, L. Food supply chain management: Systems, implementations, and future research. Ind. Manag. Data Syst. 2017, 117, 2085-2114. [CrossRef]

5. Ciaghi, A.; Villafiorita, A. Beyond food sharing: Supporting food waste reduction with ICTs. In Proceedings of the 2016 IEEE International Smart Cities Conference (ISC2), Trento, Italy, 12-15 September 2016; pp. 1-6.

6. Weymes, M.; Davies, A.R. Disruptive Technologies? Scaling Relational Geographies of ICT-Mediated Surplus Food Redistribution. In Proceedings of the 18 Conference of the European Roundtable for Sustainable Consumption and Production Society (ERSCP), Skiathos Island, Greece, 1-5 October 2017.

7. Esteso, A.; Alemany, M.; Ortiz, Á. Impact of Product Perishability on Agri-Food Supply Chains Design. Appl. Math. Model. 2021, 96, 20-38. [CrossRef]

8. Spring, C.A.; Biddulph, R. Capturing Waste or Capturing Innovation? Comparing Self-Organising Potentials of Surplus Food Redistribution Initiatives to Prevent Food Waste. Sustainability 2020, 12, 4252. [CrossRef]

9. Rut, M.; Davies, A.R.; Ng, H. Participating in food waste transitions: Exploring surplus food redistribution in Singapore through the ecologies of participation framework. J. Environ. Policy Plan. 2021, 23, 34-47. [CrossRef] 
10. Nikravech, M.; Kwan, V.; Dobernig, K.; Wilhelm-Rechmann, A.; Langen, N. Limiting food waste via grassroots initiatives as a potential for climate change mitigation: A systematic review. Environ. Res. Lett. 2020, 15, 123008. [CrossRef]

11. Bergström, P.; Malefors, C.; Strid, I.; Hanssen, O.J.; Eriksson, M. Sustainability Assessment of Food Redistribution Initiatives in Sweden. Resources 2020, 9, 27. [CrossRef]

12. Koivunen, L.; Laato, S.; Rauti, S.; Naskali, J.; Nissilä, P.; Ojansivu, P.; Mäkilä, T.; Norrdal, M. Increasing Customer Awareness on Food Waste at University Cafeteria with a Sensor-Based Intelligent Self-Serve Lunch Line. In Proceedings of the 2020 IEEE International Conference on Engineering, Technology and Innovation (ICE/ITMC), Cardiff, UK, 15-17 June 2020; pp. 1-9.

13. Spicer, L.C.; Patel, D.; Bodurtha, E.R.; Maslen, A.M. Surplus Food Management: A Case Study. Student Work, Bachelor's Thesis, Worcester Polytechnic Institute, Bangkok, Thailand, 2020.

14. Eriksson, M.; Giovannini, S.; Ghosh, R.K. Is there a need for greater integration and shift in policy to tackle food waste? Insights from a review of European Union legislations. SN Appl. Sci. 2020, 2, 1-13. [CrossRef]

15. Davies, A.R.; Cretella, A.; Franck, V. Food sharing initiatives and food democracy: Practice and policy in three European cities. Politics Gov. 2019, 7, 8-20. [CrossRef]

16. Weymes, M.; Davies, A.R. [Re] Valuing Surplus: Transitions, technologies and tensions in redistributing prepared food in San Francisco. Geoforum 2019, 99, 160-169. [CrossRef]

17. Berns, K.; Rossitto, C. From Commodities to Gifts: Redistributing Surplus Food Locally. In Proceedings of the Ethnographies of Collaborative Economies, Edinburgh, Scotland, 25 October 2019.

18. Durr, S.J.; Lotz-Sistika, H. Exploring the Social Learning Value Enabled by Affordances of the Food for Us Mobile Application: The Story of a South African Food Redistribution App. Int. Assoc. Dev. Inf. Soc. 2019, 81-88. [CrossRef]

19. Spring, C.; Adams, M.; Hardman, M. Sites of learning: Exploring political ecologies and visceral pedagogies of surplus food redistribution in the UK. Policy Futur. Educ. 2019, 17, 844-861. [CrossRef]

20. Arcuri, S. Food poverty, food waste and the consensus frame on charitable food redistribution in Italy. Agric. Hum. Values 2019, 36, 263-275. [CrossRef]

21. King, E. Identifying Arkansas Food Desert Blocks Suitable for a Peer-to-Peer Modeled Food Redistribution Program. Thesis Work, Bachelor's Thesis, University of Arkansas, Fayetteville, AR, USA, 2019.

22. Light, A.; Miskelly, C. Platforms, scales and networks: Meshing a local sustainable sharing economy. Comput. Support. Coop. Work. CSCW 2019, 28, 591-626. [CrossRef]

23. Davies, A.; Evans, D. Urban food sharing: Emerging geographies of production, consumption and exchange. Geoforum 2019, 99, 154-159. [CrossRef]

24. Duan, Y.; Cao, Y.; Huo, J. Optimal pricing, production, and inventory for deteriorating items under demand uncertainty: The finite horizon case. Appl. Math. Model. 2018, 58,331-348. [CrossRef]

25. El Bilali, H.; Allahyari, M.S. Transition towards sustainability in agriculture and food systems: Role of information and communication technologies. Inf. Process. Agric. 2018, 5, 456-464. [CrossRef]

26. Rut, M.; Davies, A.R. Sharing foodscapes: Shaping urban foodscapes through messy processes of food sharing. In Messy Ethnographies in Action; Vernon Press: Wilmington, DE, USA, 2018; pp. 167-175.

27. Facchini, E.; Iacovidou, E.; Gronow, J.; Voulvoulis, N. Food flows in the United Kingdom: The potential of surplus food redistribution to reduce waste. J. Air Waste Manag. Assoc. 2018, 68, 887-899. [CrossRef]

28. Frigo, A.; Lucchini, M. Working together towards circular economy: Recovery and redistribution of surplus food for social purposes. In Proceedings of the 6th International Conference on Sustainable Solid Waste Management, Naxos Island, Greece, 13-16 June 2018.

29. Rombach, M. New Perspectives on Food Redistribution: Evidence from the German Food Bank and Other Volunteer Based Organizations. Ph.D. Thesis, Technische Universität München, München, Germany, 2018.

30. Davies, A.R.; Legg, R. Fare sharing: Interrogating the nexus of ICT, urban food sharing, and sustainability. Food Cult. Soc. 2018, 21, 233-254. [CrossRef]

31. Davies, A.R.; Edwards, F.; Marovelli, B.; Morrow, O.; Rut, M.; Weymes, M. Making visible: Interrogating the performance of food sharing across 100 urban areas. Geoforum 2017, 86, 136-149. [CrossRef]

32. Falcone, P.M.; Imbert, E. Bringing a sharing economy approach into the food sector: The potential of food sharing for reducing food waste. In Food Waste Reduction and Valorisation; Springer: Berlin/Heidelberg, Germany, 2017; pp. 197-214.

33. Mousa, T.Y.; Freeland-Graves, J.H. Organizations of food redistribution and rescue. Public Health 2017, 152, 117-122. [CrossRef] [PubMed]

34. Vittuari, M.; De Menna, F.; Gaiani, S.; Falasconi, L.; Politano, A.; Dietershagen, J.; Segrè, A. The second life of food: An assessment of the social impact of food redistribution activities in Emilia Romagna, Italy. Sustainability 2017, 9, 1817. [CrossRef]

35. Berry, B.; Acheson, A. Sharing isn't easy: Food waste and food redistribution in Maine K-12 schools. Maine Policy Rev. 2017, $26,47-58$.

36. Ananprakrit, N.; Esbjörnsson, M. Traceability in Charitable Food Redistribution System-Ensuring Food Safety and Quality in a Cold Chain. Student Paper, Master's Thesis, Lund University, Lund, Scania, Sweden, 2017.

37. Philip, D.; Hod-Ovadia, S.; Troen, A.M. A technical and policy case study of large-scale rescue and redistribution of perishable foods by the "Leket Israel" food bank. Food Nutr. Bull. 2017, 38, 226-239. [CrossRef] [PubMed] 
38. Fleming, M. Estimating Environmental Emissions from Produce Waste Redistribution in the Capital Region. Thesis Work, Master's Thesis, University at Albany, State University of New York, Albany, NY, USA, 2017.

39. Adenso-Díaz, B.; Lozano, S.; Palacio, A. Effects of dynamic pricing of perishable products on revenue and waste. Appl. Math. Model. 2017, 45, 148-164. [CrossRef]

40. Demirag, O.C.; Kumar, S.; Rao, K.M. A note on inventory policies for products with residual-life-dependent demand. Appl. Math. Model. 2017, 43, 647-658. [CrossRef]

41. Herbon, A. A non-cooperative game model for managing a multiple-aged expiring inventory under consumers' heterogeneity to price and time. Appl. Math. Model. 2017, 51,38-57. [CrossRef]

42. Jurgilevich, A.; Birge, T.; Kentala-Lehtonen, J.; Korhonen-Kurki, K.; Pietikäinen, J.; Saikku, L.; Schösler, H. Transition towards circular economy in the food system. Sustainability 2016, 8, 69. [CrossRef]

43. Mourad, M. Recycling, recovering and preventing "food waste": Competing solutions for food systems sustainability in the United States and France. J. Clean. Prod. 2016, 126, 461-477. [CrossRef]

44. Svenfelt, A.; Zapico, J.L. Sustainable food systems with ICT. In ICT for Sustainability 2016; Atlantis Press: Amsterdam, The Netherlands, 2016.

45. Garrone, P.; Melacini, M.; Perego, A.; Sert, S. Reducing food waste in food manufacturing companies. J. Clean. Prod. 2016, 137, 1076-1085. [CrossRef]

46. Gram-Hanssen, I.; Hanssen, O.J.; Hultén, J.; Silvennoinen, K.; Werge, M.; Stenmarck, Å.; Aare, A.K. Food Redistribution in the Nordic Region: Phase II: Identification of Best Practice Models for Enhanced Food Redistribution; Nordic Council of Ministers: Copenhagen, Denmark, 2016.

47. Persson, A. Food redistribution in Stockholm: A comparative analysis of two scenarios-with and without a food bank. Thesis Work, Master's Thesis, Industrial Ecology, Royal Institute of Technology, Stockholm, Sweden, 2016.

48. Anselmo, L.C. Re-Food: A Portuguese Case Study of a Community-Based Enterprise Creating Social Capital Through Food Redistribution. Ph.D. Thesis, Portuguese Catholic University, Porto, Portugal, 2016.

49. Orgut, I.S.; Ivy, J.; Uzsoy, R.; Wilson, J.R. Modeling for the equitable and effective distribution of donated food under capacity constraints. IIE Trans. 2016, 48, 252-266. [CrossRef]

50. Vlaholias, E.; Thompson, K.; Every, D.; Dawson, D. Charity starts... at work? Conceptual foundations for research with businesses that donate to food redistribution organisations. Sustainability 2015, 7, 7997-8021. [CrossRef]

51. Capodistrias, P. Reducing Food Waste through Direct Surplus Food Redistribution: The Norwegian Case. Master's Thesis, Norwegian University of Life Sciences, Ås, Norway, 2015.

52. Silvennoinen, K.; Katajajuuri, J.M. Food redistribution in the Helsinki Metropolitan and Turku Areas. In Proceedings of the LCA for "Feeding the Planet and Energy for Life", International Conference on Life Cycle Assessment as Reference Methodology for Assessing Supply Chains and Supporting Global Sustainability Challenges, Stresa, Italy, 6-7 October 2015; Scalbi, S., Dominici Loprieno, A., Sposato, P., Eds.; ENEA: Rome, Italy, 2015.

53. Neff, R.A.; Kanter, R.; Vandevijvere, S. Reducing food loss and waste while improving the public's health. Health Aff. 2015, 34, 1821-1829. [CrossRef]

54. Lindberg, R.; Lawrence, M.; Gold, L.; Friel, S. Food rescue-an Australian example. Br. Food J. 2014, 116, 1478-1489. [CrossRef]

55. Caraher, M.; Cavicchi, A.; Garrone, P.; Melacini, M.; Perego, A. Surplus food recovery and donation in Italy: The upstream process. Br. Food J. 2014, 116, 1460-1477.

56. Garrone, P.; Melacini, M.; Perego, A. Opening the black box of food waste reduction. Food Policy 2014, 46, 129-139. [CrossRef]

57. Downing, E.; Kennedy, S.; Fell, M. Food Banks and Food Poverty; House of Commons: London, UK, 2014.

58. Kim, M.L. Food Redistribution during China's Qin and Han Periods: Accordance and Discordance among Ideologies, Policies, and Their Implementation. Ph.D. Thesis, UC Santa Barbara, Santa Barbara, CA, USA, 2014.

59. Giuseppe, A.; Mario, E.; Cinzia, M. Economic benefits from food recovery at the retail stage: An application to Italian food chains. Waste Manag. 2014, 34, 1306-1316. [CrossRef] [PubMed]

60. Furbank, L. 59 Organizations Fighting Food Loss and Waste. 2016. Available online: https://foodtank.com/news/2016/07/59 -organizations-fighting-food-loss-and-waste/ (accessed on 13 January 2021).

61. Sanyal, S.; Singh, V.K.; Xhafa, F.; Sanyal, B.; Mukhopadhyay, S. A Game Theoretic Framework for Surplus Food Distribution in Smart Cities and Beyond. arXiv 2021, arXiv:2102.04929.

62. Gale, D.; Shapley, L.S. College admissions and the stability of marriage. Am. Math. Mon. 2013, 120, 386-391. [CrossRef]

63. Roughgarden, T. CS269I: Incentives in Computer Science Lecture\# 2: Stable Matching. 2016. Available online: http:// timroughgarden.org/f16/1/12.pdf (accessed on 28 May 2021).

64. Cormen, T.H.; Leiserson, C.E.; Rivest, R.L.; Stein, C. Introduction to Algorithms; MIT Press: Cambridge, MA, USA, 2009. 